Jéssica Natália da Costa Dantas

\title{
Propagação eletrônica em um fio quântico submetido a uma interação spin-órbita e a um potencial químico modulados
}

\author{
Brasília
}

11 de novembro de 2015 
Jéssica Natália da Costa Dantas

\title{
Propagação eletrônica em um fio quântico submetido a uma interação spin-órbita e a um potencial químico modulados
}

\begin{abstract}
Dissertação apresentada como requisito parcial para obtenção do grau de Mestre em Ciência de Materiais pelo Programa de Pós-Graduação em Ciência de Materiais da Faculdade UnB Planaltina da Universidade de Brasília.
\end{abstract}

\author{
Universidade de Brasília \\ Faculdade UnB Planaltina \\ Programa de Pós-Graduação em Ciência de Materiais
}

Orientador: Prof. Dr. Paulo Eduardo de Brito

Brasília

11 de novembro de 2015 
Jéssica Natália da Costa Dantas

Propagação eletrônica em um fio quântico submetido a uma interação spinórbita e a um potencial químico modulados/ Jéssica Natália da Costa Dantas. Brasília, 11 de novembro de 2015-

67 p. : il. (algumas color.) ; $30 \mathrm{~cm}$.

Orientador: Prof. Dr. Paulo Eduardo de Brito

Dissertação (mestrado) - Universidade de Brasília

Faculdade UnB Planaltina

Programa de Pós-Graduação em Ciência de Materiais , 11 de novembro de 2015.

CDU 02:141:005.7 
Jéssica Natália da Costa Dantas

\title{
Propagação eletrônica em um fio quântico submetido a uma interação spin-órbita e a um potencial químico modulados
}

\begin{abstract}
Dissertação apresentada como requisito parcial para obtenção do grau de Mestre em Ciência de Materiais pelo Programa de Pós-Graduação em Ciência de Materiais da Faculdade UnB Planaltina da Universidade de Brasília.
\end{abstract}

Trabalho aprovado. Brasília, 11 de novembro de 2015:

\begin{tabular}{c} 
Presidente/Orientador \\
Prof. Dr. Paulo Eduardo de Brito \\
Fup/UnB \\
\hline Titular \\
IF/UnB \\
Prof. Dr. Hugo Nicolas Nazareno \\
Titular \\
Prof. Dr. Bernhard Georg Enders Neto \\
Fup/UnB \\
Brasília \\
11 de novembro de 2015
\end{tabular}


A minha mãe Cláudia, pelo amor, apoio, confiança e motivação. 


\section{Agradecimentos}

Primeiramente quero agradecer a Deus pelo dom da vida.

Ao meu orientador, Prof. Dr. Paulo Eduardo de Brito, por quem tenho imensa admiração. Obrigada pela orientação, paciência, bom humor e por tudo que contribuiu para formação como um todo.

A minha coorientadora Prof. Dra. Mariana Malard pelas valiosas contribuições desde os tempos da graduação.

As minhas amigas Camila e Isabella pelo incentivo e momentos de alegria que vivemos juntas.

Ao Deivisson por todo amor, carinho, paciência e apoio.

A toda minha família, e em especial a tia Raquel que tenho imensa gratidão e admiração e a minha avó Neusa, por todo carinho e amor desde sempre.

Ao meu pai pelo apoio e a minha mãe pelo amor, incentivo e confiança.

À CAPES pelo incentivo financeiro. 
A mente que se abre a uma nova idéia jamais voltará ao seu tamanho original.

Albert Einstein 


\section{Resumo}

Neste trabalho foram estudadas as propriedades de transporte de um pacote de onda em um fio quântico submetido a um campo elétrico externo modulado e levando em consideração a interação spin-órbita do tipo Rashba e Dresselhaus. Nesse sistema, a interação spin-órbita Dresselhaus possibilita a inversão do spin do elétron injetado. Para analisar a evolução temporal do sistema (partículas) que avaliar os seguintes parâmetros: a probabilidade de retorno do elétron, o desvio quadrático médio (MSD), a função participação e o centro do pacote de onda. Foi observado que determinados valores dos parâmetros localiza a função de onda, podendo fazer uma correlação com transição de fase metal-isolante ou estado localizado e não localizado.

Palavras-chaves: Propriedades de transporte. Interação spin-órbita. Rashba. Dresselhaus. 


\section{Abstract}

In this work we present results obtained on the transport properties of a wave packet in a quantum wire subjected to an external modulated electric field and taking into account the spin-orbit interaction of the Rashba and Dresselhaus types. In this system the Dresselhaus spin-orbit interaction produces the reversal of the spin of the injected electron. To analyze the time evolution of the system (particle) we evaluate the following parameters: the return probability of electron, the root mean square deviation (MSD) function participation and the center of the wave packet. It was observed that for certain parameter values the wave function is localized in a certain region which allows to make a correlation with a metal-insulator phase transition.

Keywords: Transport properties. Spin-orbit interaction. Rashba. Dressehaus. 


\section{Sumário}

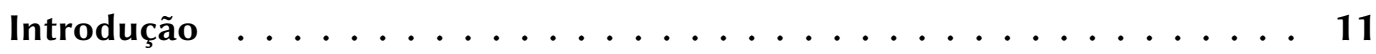

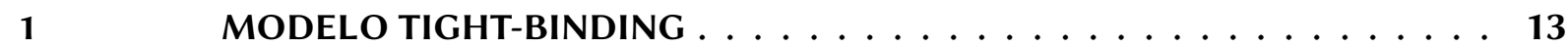

1.1 Considerações Preliminares $\ldots \ldots \ldots \ldots \ldots \ldots$

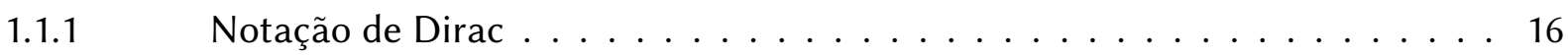

1.1.2 Base de Wannier . . . . . . . . . . . . . . . . . . 16

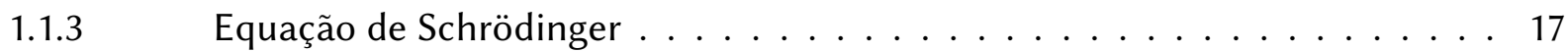

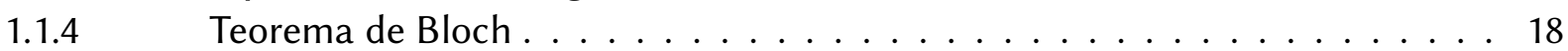

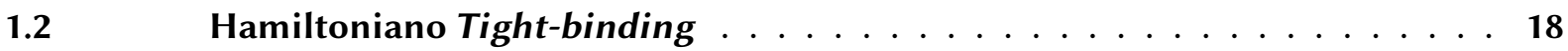

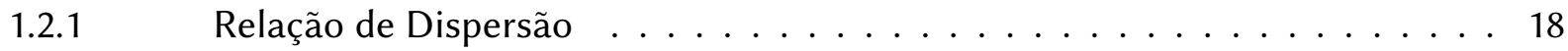

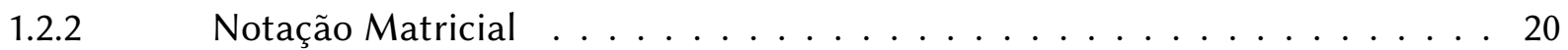

$1.3 \quad$ Condições iniciais e medidas de transporte $\ldots \ldots \ldots \ldots$

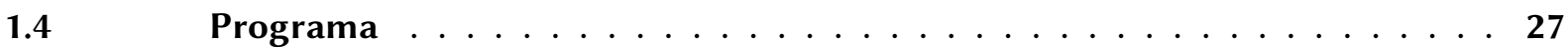

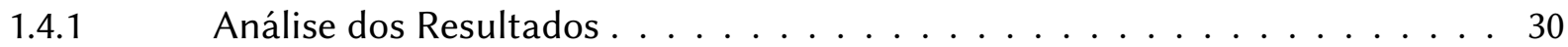

2 MODELO DE UM FIO QUÂNTICO COM INTERAÇÕES SPIN-ÓRBITA SUBMETIDO A UM CAMPO ELÉTRICO MODULADO . . . . . . . . . . . . 35

$2.1 \quad$ Hamiltoniano de elétrons não interagentes $\ldots \ldots \ldots \ldots \ldots$

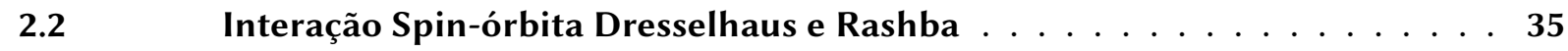

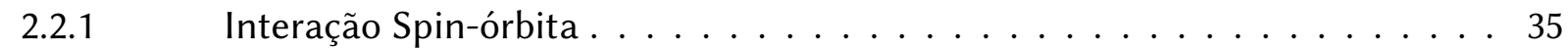

2.2.2 Hamiltoniano Dresselhaus e Rashba . . . . . . . . . . . . . . . . . 36

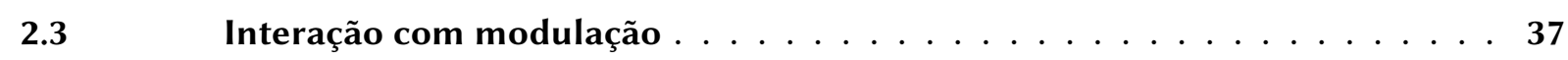

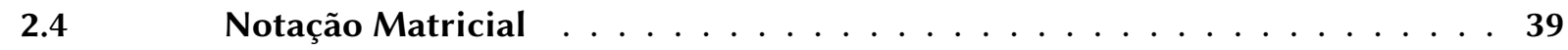

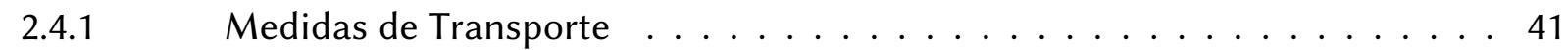

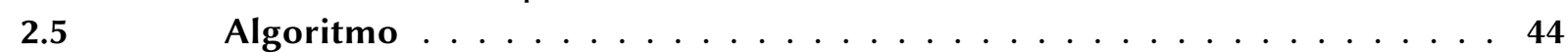

$2.6 \quad$ Bandas de Energia $\ldots \ldots \ldots \ldots \ldots \ldots$

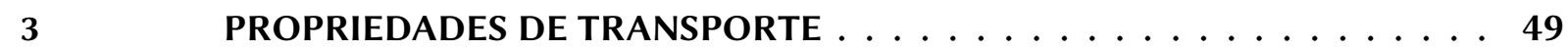

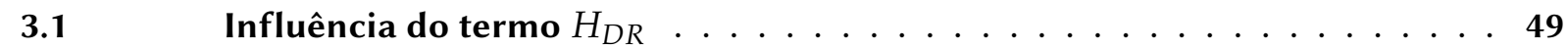

$3.2 \quad$ Influência dos termos do $H_{m o d} \ldots \ldots \ldots \ldots \ldots \ldots \ldots$

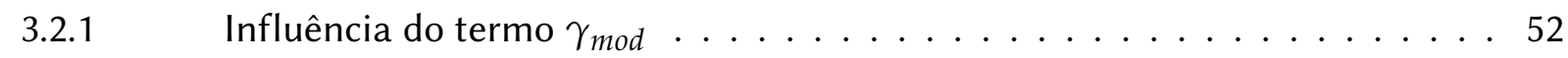

3.2.2 Influência do termo $\gamma_{\text {mod }}$ com $\mathrm{k}=0.5 \ldots \ldots \ldots \ldots \ldots$

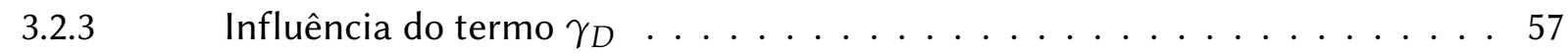

$3.3 \quad$ Influência do número de onda da modulação externa $\ldots \ldots \ldots$

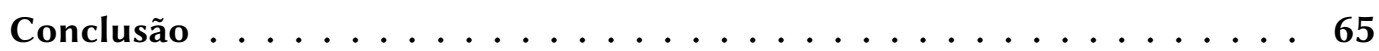

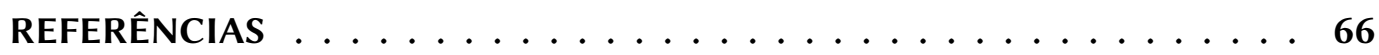




\section{Lista de símbolos}

$k \Rightarrow$ Número de onda (em unidades de $\frac{\pi}{a}$ ).

$p=\hbar k \Rightarrow$ Momento Linear.

$\sigma \Rightarrow$ Largura da gaussiana (em unidades de $a$ ).

$W \Rightarrow$ Energia de Hopping.

$\mu \Rightarrow$ Potencial químico (em unidades de W).

$\mu_{\text {mod }} \Rightarrow$ Potencial químico modulado (em unidades de $\mathrm{W}$ ).

$\gamma_{D} \Rightarrow$ Intensidade da interação Dresselhaus (em unidades de W).

$\gamma_{R} \Rightarrow$ Intensidade da interação Rashba (em unidades de W).

$\gamma_{R_{\text {mod }}} \Rightarrow$ Intensidade da interação Rashba modulada (em unidades de $W)$.

$H_{0} \Rightarrow$ Hamiltoniano tight-binding.

$H_{D R} \Rightarrow$ Hamiltoniano Spin-órbita Dresselhaus Rashba.

$H_{\text {mod }} \Rightarrow$ Hamiltoniano Modulado.

$H_{D} \Rightarrow$ Hamiltoniano Dresselhaus.

$H_{R} \Rightarrow$ Hamiltoniano Rashba.

$q \Rightarrow$ Número de onda do potencial modulado.

$\tau \Rightarrow$ Spin rotacionado.

$\tau \Rightarrow$ (unidades de tempo em $\hbar / W$ )

$\gamma_{e f f} \Rightarrow \sqrt{\gamma_{R}^{2}+\gamma_{D}^{2}}$

$\gamma_{\text {mod }} \Rightarrow$ Intensidade da interação modulada (em unidades de $W$ ). 


\section{Introdução}

Spintrônica é um campo multidisciplinar cujo tema central é o controle e manipulação ativo de graus de rotação de spin em sistema do estado sólido [1]. O spin corresponde a um grau de liberdade interno do elétron, e embora as vezes seja descrito de forma aproximada como o movimento do elétron em torno do seu próprio eixo, é uma propriedade intrínseca da partícula (assim como sua massa e sua carga) [2].

Semicondutores são materiais que dispertam grande interesse na área da spintrônica. Diversas propriedades eletrônicas são baseadas no entendimento do comportamento dos semicondutores e uma das grandes vantagens desses materiais é a possibilidade de mudar sua característica de isolante para condutor com facilidade, através da retirada de elétrons ou da inserção de impurezas na estrutura cristalina.

A capacidade de controlar e manipular elétrons em semicondutores ocorre por meio de um campo elétrico externo que constitui a base da tecnologia spintrônica atual. Dispositivos podem ser criados baseados na manipulação do grau de liberdade do spin, como o transistor de spintrônica que é um exemplo desse tipo de dispositivo [3].

Datta e Das [4] propuseram um modelo de transistor que utiliza a spintrônica, que consiste em uma técnica em que os elétrons com spin polarizados são injetados a partir de um emissor ferromagnético dentro de um fio quântico modelado em uma heteroestrutura semicondutora que está sujeito a um campo externo. Porém, essa técnica de injeção de spin não tem sido eficiente para todas as propriedades esperadas desse transistor intitulado Datta-Das [5], e novas técnicas de injeção de spins tem sido estudadas [6] [7].

Em um trabalho recente, Malard et. al. [5] propuseram um modelo de dispositivo controlável por uma modulação externa, em que se dispensa a necessidade de injetar elétrons com spin polarizados. Verificou-se que o acoplamento spin-órbita Rashba suavemente modulado em um fio quântico impulsiona uma transição de fase de metal para isolante, quando o número de onda da modulação torna-se proporcional ao comprimento de onda de Fermi no fio. A interação spin-órbita causa troca de spin dos elétrons injetados, de acordo com o campo externo aplicado, que ao entrar em contato com o coletor ferromagnético tais elétrons são aceitos ou não, baseados na sua orientação de spin.

Neste trabalho temos como objetivo estudar o comportamento dos elétrons em um fio quântico submetido a uma interação spin-órbita e a um potencial químico modulado controláveis através de uma modulação externa. 
Este trabalho está organizado em três capítulos que foram divididos em seções e subseções. No capítulo 1, abordamos de forma simples a propagação eletrônica em sistemas unidimensionais através do modelo tight-binding. No capítulo 2, apresentamos a explicação física dos vários termos do hamiltoniano, baseada no estudo feito por Malard et. al. [5]. No capítulo 3, analisamos os resultados obtidos a partir das simulações. 


\section{Modelo Tight-binding}

\subsection{Considerações Preliminares}

O objetivo deste capitulo é estudar o comportamento da função de onda do elétron em uma rede cristalina unidimensional utilizando o modelo tight-binding.

O sistema físico é descrito pelo comportamento dos elétrons e íons da rede cristalina. Nesse modelo os íons (núcleo atômico somado aos elétrons ligados exclusivamente a estes núcleos) são considerados inertes, pois o movimento eletrônico é muito mais rápido do que dos íons. Dessa maneira o estudo se restringe aos elétrons, que podem ser divididos em dois grupos. O primeiro, os elétrons que estão fortemente ligados aos núcleos positivos formando assim os íons; e o segundo grupo, formado pelos elétrons que estão na camada de valência de cada átomo. Esses elétrons, que podem transitar entre um átomo e outro, estão sujeitos a um potencial periódico que representa a interação com os íons localizados na rede. Um outro fator importante é a não consideração da interação entre os elétrons, desse modo pode-se estudar o comportamento de um único elétron e a partir daí inferir o comportamento do sistema como um todo.

Quando consideramos um único átomo, os elétrons ligados a esse átomo tem energias bem específicas, energias quantizadas. Quando átomos desse tipo se aproximam um do outro, os níveis de energia sofrem variações ocasionadas pela superposição das distribuições de carga de cada um desses átomos. Por exemplo, consideremos dois átomos de hidrogênio cada um com um elétron no estado fundamental. As funções de onda $\psi_{a}$ e $\psi_{b}$ de átomos separados com mostra na Fig. 1 (a) se superpõem a medida que seus átomos se aproximam. Quando ocorre a soma das funções de onda $\psi_{a}+\psi_{b}$ como mostra na Fig. 1 (b) o elétron fica maior parte do tempo entre os dois prótons, ou seja, no potencial de atração entre os prótons, aumentando assim a energia de ligação. No estado $\psi_{a}-\psi_{b}$ como mostra na Fig. 1 (c), não aparece uma ligação extra pois existe uma inteferência destrutiva entre as funções de onda. Na Fig. 1 (b), $\psi_{a}+\psi_{b}$, o elétron possui uma energia inferior a energia do estado na Fig. 1 (c), $\psi_{a}-\psi_{b}$. Diz-se então que o estado $\psi_{a}-\psi_{b}$ é um estado excitado ou de mais alta energia [8, p. 257] 


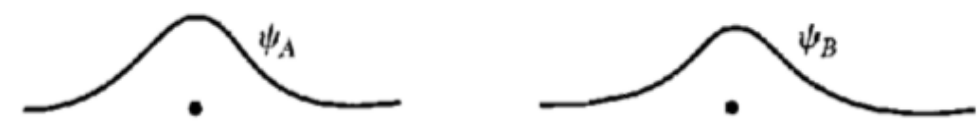

(a)

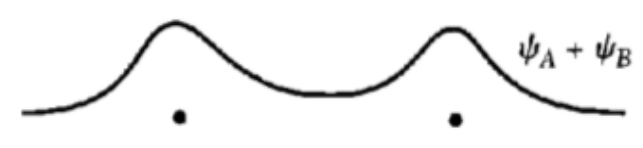

(b)

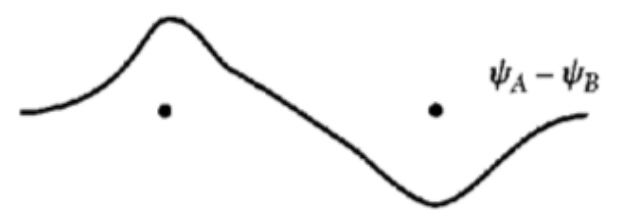

(c)

Figura 1 - (a) Função de onda de dois átomos quando a distância entre eles é grande, (b) Soma das funções de onda de dois átomos quando esta distância é maior, (c) Função de onda com energia mais alta. Figura tirada de [8, p. 257]

Quando ao invés de dois átomos se aproximando, tivermos $\mathrm{N}$ átomos (formando uma rede) tem-se $\mathrm{N}$ orbitais para cada orbital do átomo isolado, dessa maneira formase uma faixa quase contínua de energia em torno da energia de um único átomo. Essa faixa é chamada de banda de energia permitida. E a região que não existe energias possíveis é chamada de espaçamento entre as bandas entre bandas de energia (gap). 


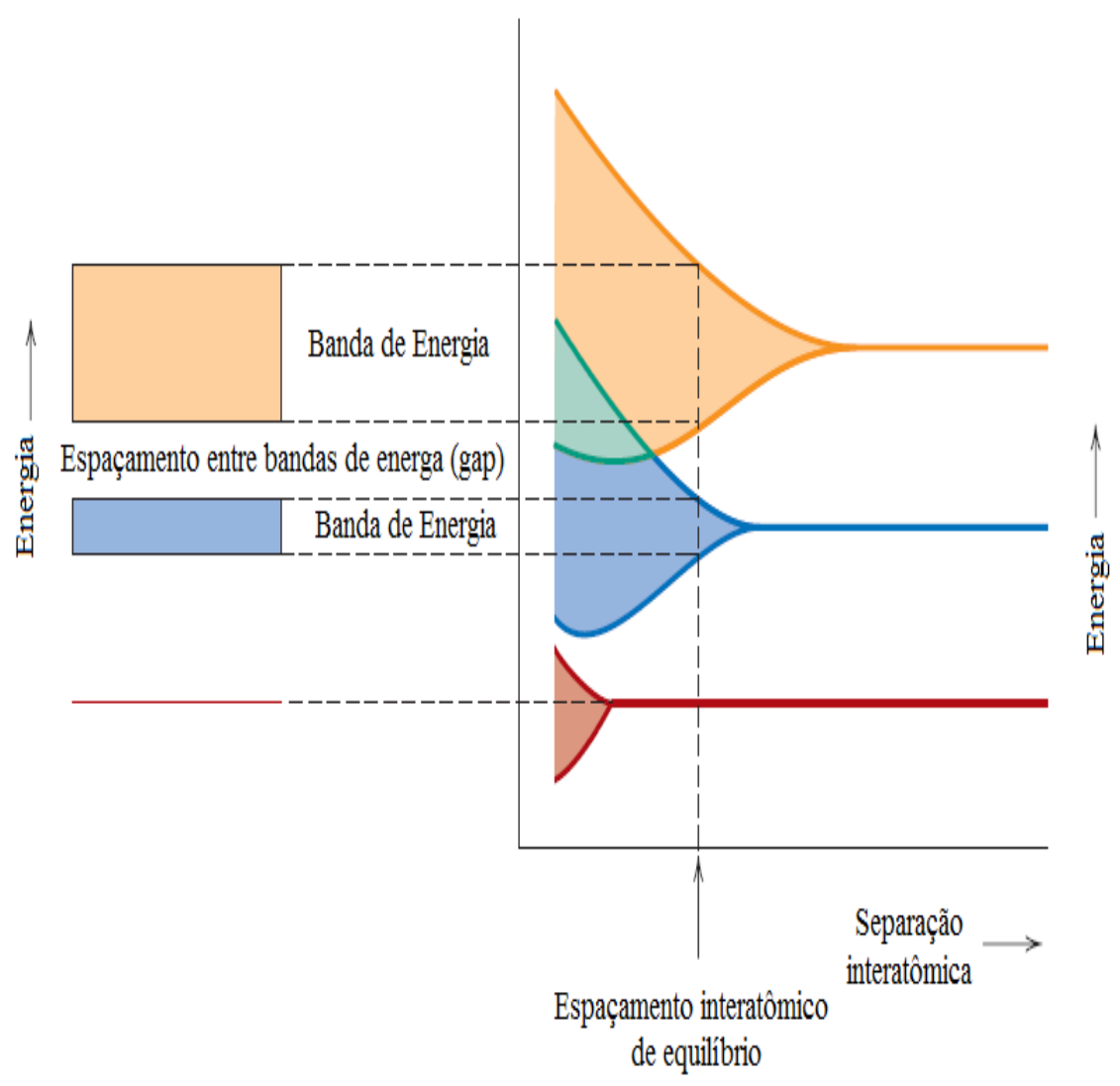

(a)

(b)

Figura 2 - A pertubação devido a proximidade pode dividir cada estado atômico em um conjunto de estados eletrônicos muito próximos entre si que não existiam nos átomos isolados. (a) A representação convencional da estrutura da banda de energia eletrônica para um material sólido na separação interatômica de equilibrio. (b) A energia eletrônica em função da separação interatômica para um agregado de átomos, ilustrando como é gerada a estrutura da banda de energia na separação de equilibrio em (a). Figura tirada de [9]

A diferença entre condutores e isolantes está na ocupação e distribuição da banda. A quantidade de elétrons livres vai definir o tipo de material. A presença de gaps nas bandas é outro fator importante na definição da diferença.

Se existe uma quantidade considerável de elétrons livres na banda o material é considerado condutor. Mas se a banda está totalmente preenchida, e não existe elétrons livres na banda, ou a quantidade é tão pequena que pode ser desconsiderada, esse material é considerado isolante.

Nos condutores, os gaps (espaçamentos entre as bandas) é estritamente pequeno, e assim qualquer pequena energia ocasiona uma excitação e liberta os elétrons. 
Enquanto que nos isolantes o espaçamento é consideravelmente maior, o que dificulta a passagem do elétron para outra banda [9]. Já nos semicondutores, o tamanho do espaçamento é menor se comparado com o dos isolantes.

Semicondutores são materiais que, apesar de não servirem como bons condutores, nem como bons isolantes, são considerados materiais especiais, porque a presença de impurezas pode torná-los bons condutores ou bons isolantes. Esses materiais são muito utilizados para criar transistores, chips entre outros.

Mais adiante neste trabalho, não abordamos sobre a estrutura ser isolante ou condutora. Como o trabalho foi baseado no comportamente da função de onda de apenas um elétron, falamos sobre a função de onda estar localizada e não localizada.

Antes de introduzir o modelo propriamente dito, será interessante recordar ou introduzir alguns conceitos úteis que serão utilizados mais adiante.

\subsubsection{Notação de Dirac}

Neste trabalho iremos utilizar a notação de Dirac [10, p. 108] para representar os estados eletrônicos.

O "ket" $|\Psi\rangle$ representa o estado do elétron, tal que a função eletrônica no espaço real é dada por:

$$
\Psi(x)=\langle x \mid \Psi\rangle
$$

e o bra $\langle x|$ representa a base do espaço real. Dessa maneira $\Psi(x)$ é a projeção do estado $|\Psi\rangle$ no espaço real.

\subsubsection{Base de Wannier}

Para o sistema estudado utilizamos a base de Wannier [11], que é formada pelo conjunto de estados localizado em cada sítio. $|n\rangle$ representa o estado do elétron quando está nas proximidades do sítio $n$ tal que $\langle x \mid n\rangle=\phi_{n}(x)$ é o orbital atômico referente ao elétron de valência do átomo localizado no sítio $n$.

Uma outra base importante e utilizada é a base recíproca de $|n\rangle$ dada pela sua transformada de Fourier, representada por $|k\rangle$. Nesta base, o $k$ (número de onda) está ligado ao momento linear da particula $(p=\hbar k)$.

Para obter a base $|k\rangle$, temos:

$$
|k\rangle=\sum_{n} e^{-i k n a}|n\rangle
$$


onde $a$ é o parâmetro de rede do cristal.

De maneira similar, com a transformada inversa, podemos obter a base $|n\rangle$ em função da base $|k\rangle$ :

$$
|n\rangle=\sum_{k} e^{i k n a}|k\rangle
$$

Dessa maneira, pode-se obter que o produto entre $|n\rangle$ e $|k\rangle$ é dado por:

$$
\begin{aligned}
& \langle k \mid n\rangle=e^{-i k n a} \\
& \langle n \mid k\rangle=e^{+i k n a}
\end{aligned}
$$

E temos que:

$$
\Psi(k)=\langle k \mid \Psi\rangle
$$

é a projeção do estado $|\Psi\rangle$ no espaço recíproco.

Essas relações serão úteis mais adiante.

\subsubsection{Equação de Schrödinger}

A equação de Schrödinger é uma equação fundamental da mecânica quântica, a sua solução representa a evolução temporal da função de onda que representa a partícula em estudo. É dada por:

$$
i \hbar \frac{\partial}{\partial t}|\Psi\rangle=\hat{H}|\Psi\rangle
$$

onde $\hat{H}$ é o hamiltoniano do sistema, operador este que está ligado as energias possíveis que pode surgir no sistema estudado.

Para o caso estacionário a aplicação do operador $\hat{H}$ sobre o estado $|\Psi\rangle$ irá nos trazer os níveis de energias possíveis que surgem no sistema.

$$
\hat{H}\left|\Psi_{v}\right\rangle=\epsilon_{v}\left|\Psi_{v}\right\rangle
$$

$\epsilon_{v}$ são as energias possíveis (autoenergias) e $\left|\Psi_{v}\right\rangle$ são os autoestados associados a estas autoenergias.

Uma das formas de resolver a equação de Schrödinger consiste em encontrar as autoenergias e os autoestados do sistema estudado. Dessa maneira podemos descrever 
a função de onda que representa a partícula como uma combinação linear dos autoestados e com isso resolver a evolução temporal da função de onda. Esse caminho é possível quando o hamiltoniano for linear

$$
\left|\Psi_{0}\right\rangle=\sum a_{v}\left|\Psi_{v}\right\rangle
$$

para resolver a eq. (1.6), utilizamos a eq. (1.7) e considerando a eq. (1.8), temos:

$$
|\Psi(t)\rangle=\sum a_{v} e^{-i \epsilon_{v} t / \hbar}\left|\Psi_{v}\right\rangle
$$

Ao diagonalizar $\hat{H}$, temos quais os níveis de energia possíveis e a evolução temporal da função de onda e consequentemente como a partícula se comporta no decorrer do tempo.

\subsubsection{Teorema de Bloch}

Para obedecer o Teorema de Bloch sobre a simetria da translação a solução da equação de Schrödinger num potencial periódico de uma rede cristalina unidimensional tem uma forma especial [8, p. 185]

$$
\psi_{k}(x)=U_{k}(x) e^{i k x}
$$

onde $U_{k}(x)=U_{k}(x+a)$ é uma função com periodicidade igual à da rede cristalina.

O Teorema de Bloch, dado pela Eq. (1.10), afirma serem as soluções da equação de Schrödinger com um potencial periódico um produto de uma onda plana $e^{i k x}$ por uma função $U_{k}(x)$ que possui a periodicidade da rede cristalina.

\subsection{Hamiltoniano Tight-binding}

O modelo tight-binding tem como base a aproximação que começa pelas funções de ondas dos átomos livres, e é conhecido por aproximação de ligação compacta ou combinação linear dos orbitais localizados nos sítios atômicos.

\subsubsection{Relação de Dispersão}

Veremos agora que $|k\rangle$ é um autoestado do Hamiltoniano e calcularemos a autoenergia correspondente $\epsilon(k)$. A função $\epsilon(k)$ é conhecida como relação de dispersão, 
sendo dada pelo valor esperado do Hamiltoniano do sistema no estado $|k\rangle$ :

$$
\epsilon(k)=\langle k|\hat{H}| k\rangle
$$

Usando a relação de completeza [10]:

$$
\sum_{n}|n\rangle\langle n|=\mathbb{1}
$$

Temos que:

$$
\epsilon(k)=\left\langle k\left|\left(\sum_{n}|n\rangle\langle n|\right) H\left(\sum_{m}|m\rangle\langle m|\right)\right| k\right\rangle
$$

obtemos:

$$
\epsilon(k)=\sum_{n, m}\langle k \mid n\rangle\langle m \mid k\rangle\langle n|H| m\rangle
$$

Utilizando as relações (1.4), obtemos:

$$
\epsilon(k)=\sum_{n, m} e^{i k(m-n) a}\langle n|H| m\rangle
$$

Quais energias provenientes da interação entre átomos distintos são relevantes? Apenas aquelas em que há superposição dos orbitais atômicos. Assim, na aproximação tight-binding considera-se apenas: $n=m$ e $n=m \pm 1$.

O hamiltoniano tight-binding é escrito da seguinte forma:

$$
\hat{H}=-W \sum_{n}(|n\rangle\langle n+1|+| n+1\rangle\langle n|)+\epsilon_{n}|n\rangle\langle n|
$$

onde $W$ representa a energia de hopping (Custo energético para soltar um elétron de um sítio para o sítio vizinho) e $\epsilon_{n}$ a energia de cada sítio. Onde $\epsilon_{n}=\epsilon_{0}$ para o caso cristalino de uma única componente.

Então:

$$
\langle n|H| m\rangle=\left\{\begin{array}{cc}
-\epsilon_{0} & n=m \\
-W & n=m \pm 1 \\
0 & \text { outras situações }
\end{array}\right.
$$


Utilizando a delta de Kronecker $\delta_{n, m}=\left\{\begin{array}{lll}1 & \text { se } & n=m \\ 0 & \text { se } & n \pm m\end{array}\right.$, podemos escrever as auto-energias $\epsilon(k)$ como:

$$
\begin{gathered}
\epsilon(k)=\sum_{n, m} e^{i k(m-n) a}\left(-\epsilon_{0} \delta_{n, m}-W \delta_{n, m \pm 1}\right) \\
\epsilon(k)=\epsilon_{0}-W\left(e^{i k a}+e^{-i k a}\right) \\
\epsilon(k)=-\epsilon_{0}-2 W \cos (k a)
\end{gathered}
$$

Assim é encontrada a relação de dispersão do modelo e ao mesmo tempo verificamos que $|k\rangle$ é um autoestado do hamiltoniano.

\subsubsection{Notação Matricial}

O objetivo desta seção é introduzir uma notação mais apropriada para a simulação numérica.

Seja o estado eletrônico $|\Psi\rangle$ na base de Wannier:

$$
|\Psi\rangle=\sum_{n} C_{n}|n\rangle
$$

tal que $\left|C_{n}\right|^{2}$ é a probabilidade de encontrar o elétron no sítio $n$.

Substituindo as equações (1.11) e (1.15) na Equação de Schrödinger (1.6), para obtermos como a função de onda se comporta no decorrer do tempo, temos:

$$
\begin{gathered}
i \hbar \frac{\partial}{\partial t} \sum_{n} C_{n}|n\rangle=\sum_{n, n^{\prime}}\left[\left(-W\left|n^{\prime}+1\right\rangle\left\langle n^{\prime}|+| n^{\prime}\right\rangle\left\langle n^{\prime}+1\right|\right)+\epsilon_{n}\left|n^{\prime}\right\rangle\left\langle n^{\prime}\right|\right] C_{n}|n\rangle \\
\sum_{n}\left(i \hbar \frac{\partial}{\partial t} C_{n}\right)|n\rangle=\sum_{n}\left(-W\left(C_{n+1}+C_{n-1}\right)+\epsilon_{0} C_{n}\right)|n\rangle
\end{gathered}
$$


Vamos reescrever a Eq. (1.17) na forma matricial:

$$
i \hbar \frac{\partial}{\partial t}\left(\begin{array}{c}
C_{1} \\
C_{2} \\
C_{3} \\
\vdots \\
C_{n} \\
\vdots \\
C_{N}
\end{array}\right)=\left(\begin{array}{ccccc}
\epsilon_{0} & -W & 0 & 0 & \ldots \\
-W & \epsilon_{0} & -W & 0 & \ldots \\
0 & -W & \epsilon_{0} & -W & \ldots \\
0 & 0 & -W & \epsilon_{0} & \ldots \\
\vdots & \vdots & \vdots & \vdots & \ddots
\end{array}\right)\left(\begin{array}{c}
C_{1} \\
C_{2} \\
C_{3} \\
\vdots \\
C_{n} \\
\vdots \\
C_{N}
\end{array}\right)
$$

onde $\vec{f}$ é o vetor coluna que contém os coeficientes $C_{n}$ e $M$ a matriz que representa o Hamiltoniano $\mathrm{H}$.

A solução formal desta equação diferencial é imediata.

$$
\vec{f}=e^{-i M t / \hbar} \vec{f}_{0}
$$

A exponencial de uma matriz pode ser expressa através de uma expansão em série de Taylor:

$$
e^{M}=\mathbb{1}+M+\frac{M M}{2 !}+\frac{M M M}{3 !}+\cdots
$$

A expressão acima toma uma forma simplificada se a matriz $\boldsymbol{M}$ puder ser diagonalizada. Neste caso, a matriz $\boldsymbol{M}$ pode ser escrita da seguinte forma [12]:

$$
\boldsymbol{M}=\boldsymbol{R}^{t} \mathrm{D}
$$

onde $\boldsymbol{D}$ é a matriz diagonal que tem como elementos da diagonal os autovalores $M, R$ é a matriz onde as colunas são autovetores de $M$ e $R^{t}$ é a matriz transposta de $R$.

Para simplificar, utilizando da ortonormalidade entre os autovetores, temos que:

$$
\boldsymbol{R}^{t} \boldsymbol{R}=\mathbb{1}
$$

Assim a exponecial de uma matriz $\boldsymbol{M}$ tem a seguinte forma:

$$
e^{M}=\mathbb{1}+\boldsymbol{R}^{t} \boldsymbol{D} \boldsymbol{R}+\frac{\boldsymbol{R}^{t} D R R^{t} D R}{2 !}+\frac{\boldsymbol{R}^{t} D R R^{t} D R R^{t} D R}{3 !} \ldots
$$


Simplificando:

$$
\begin{gathered}
e^{M}=\boldsymbol{R}^{t} \boldsymbol{R}+\boldsymbol{R}^{t} \boldsymbol{D} \boldsymbol{R}+\frac{\boldsymbol{R}^{t} \boldsymbol{D D} \boldsymbol{R}}{2 !}+\frac{\boldsymbol{R}^{t} \boldsymbol{D D D} \boldsymbol{R}}{3 !} \cdots \\
e^{M}=\boldsymbol{R}^{t}\left(\mathbb{1}+\boldsymbol{D}+\frac{\boldsymbol{D} \boldsymbol{D}}{2 !}+\frac{\boldsymbol{D D D}}{3 !} \cdots\right) \boldsymbol{R}
\end{gathered}
$$

E assim obtemos a exponencial da matriz $M$ em função da exponencial da matriz diagonal $\boldsymbol{D}$

$$
e^{M}=R^{t} e^{D} R
$$

Escrevendo:

$$
\boldsymbol{D}=\left(\begin{array}{ccccc}
\lambda_{1} & 0 & 0 & 0 & \cdots \\
0 & \lambda_{2} & 0 & 0 & \cdots \\
0 & 0 & \lambda_{3} & 0 & \cdots \\
0 & 0 & 0 & \lambda_{4} & \cdots \\
\vdots & \vdots & \vdots & \vdots & \ddots
\end{array}\right)
$$

vem que:

$$
e^{D}=\left(\begin{array}{ccccc}
e^{\lambda_{1}} & 0 & 0 & 0 & \cdots \\
0 & e^{\lambda_{2}} & 0 & 0 & \cdots \\
0 & 0 & e^{\lambda_{3}} & 0 & \cdots \\
0 & 0 & 0 & e^{\lambda_{4}} & \cdots \\
\vdots & \vdots & \vdots & \vdots & \ddots
\end{array}\right)
$$

onde $\lambda_{i}$ são os autovalores de $M$.

Substituindo a Eq. (1.22) na Eq. (1.20), temos:

$$
\begin{gathered}
\vec{f}=\boldsymbol{R}^{t} e^{-i \boldsymbol{D} t / \hbar} \boldsymbol{R} \vec{f}_{0} \\
\vec{f}=\boldsymbol{R}^{t}\left[\cos \left(\boldsymbol{D} \frac{t}{\hbar}\right)-i \operatorname{sen}\left(\boldsymbol{D} \frac{t}{\hbar}\right)\right] \boldsymbol{R} \vec{f}_{0}
\end{gathered}
$$

A função $\cos (\boldsymbol{D})$ é uma matriz diagonal cujos elementos da diagonal são dados por $\cos \left(\lambda_{i}\right)$. A função $\operatorname{sen}(D)$ é dada de forma análoga.

Com isso temos a evolução temporal de $\vec{f}$ que representa o estado eletrônico. 
A vantagem de utilizar métodos de diagonalização de matriz é porque obtemos quais são os autovalores, os estados primitivos do sistema e a solução é obtida de forma mais rápida.

Com a Eq. (1.24) obtemos os autovalores e autovetores. Ao encontrar todos os autovalores teremos todas as energias do sistema. No caso do sistema tight-binding, as energias possíveis do sistema formam uma estrutura contínua, sem gaps, o que identifica o sistema como um condutor. A Fig. 3 mostra a banda contínua de energia do modelo tight-binding, tomando $\epsilon_{n}=0$ para as energias de sítio.

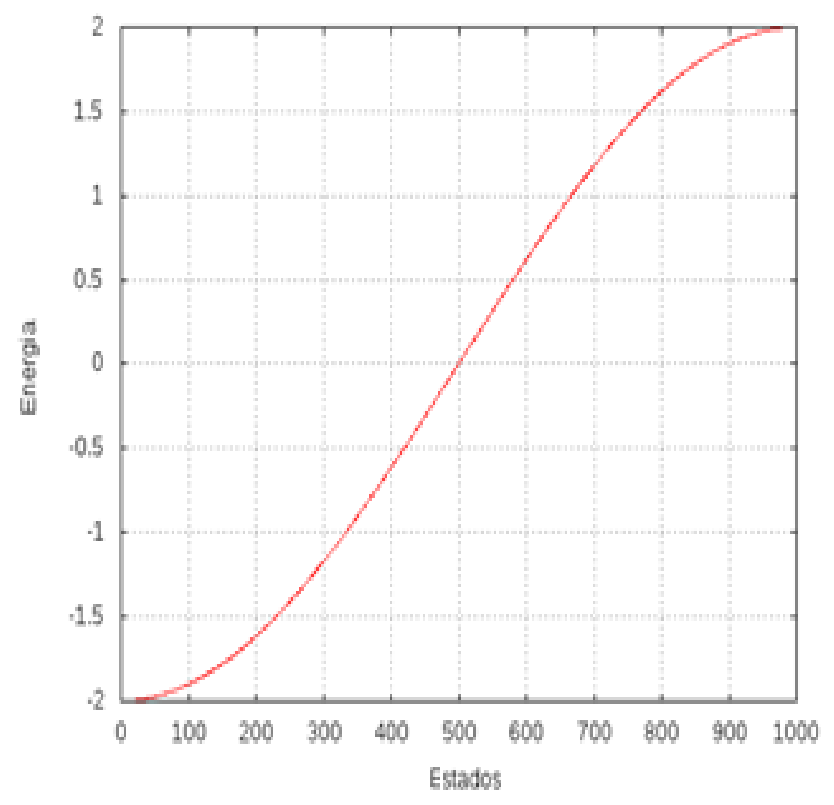

Figura 3 - Autoenergias do modelo tight-binding: banda contínua, sem gaps.

Se a energia de sítio não for uniforme - o que pode acontecer, por exemplo, se o material for composto por duas ou mais espécies de átomos ou em virtude de um campo externo - irá aparecer mais de uma banda de energia, surgindo regiões de energia proibidas, ou gaps de energia.

A Fig. 4 ilustra a situação em que a energia de sítio $\epsilon_{n}=0(1)$ se $n$ for ímpar (par). Um gap se abre no meio da banda de energia. 


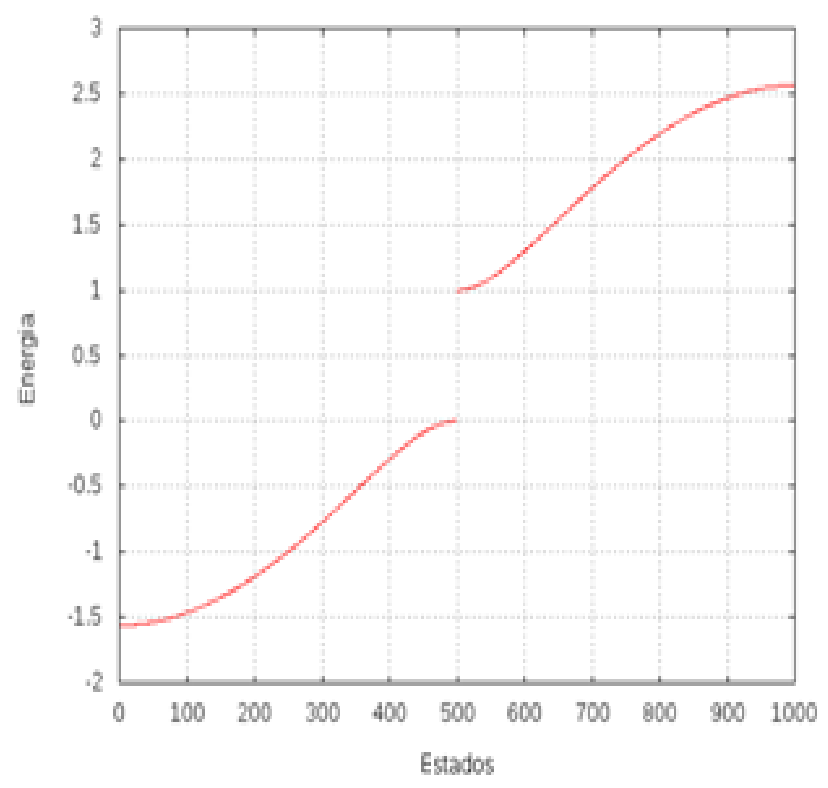

Figura 4 - Auto-energias do modelo tight-binding com energia de sítio $\epsilon_{n}=0$ (sítios ímpares) e $\epsilon_{n}=1$ (sítios pares): gap se abre no meio da banda de energia.

\subsection{Condições iniciais e medidas de transporte}

Assim realizadas, as condições iniciais para evolução da função de onda dadas na eq. (1.15) são dadas por uma gaussiana em conjunto com ondas planas. O pacote de onda inicial esta centralizado no sitio $n_{0}$, com largura $\sigma$ e momento linear $\hbar k$. Esse pacote de onda é obtido tomando-se na eq. (1.15).

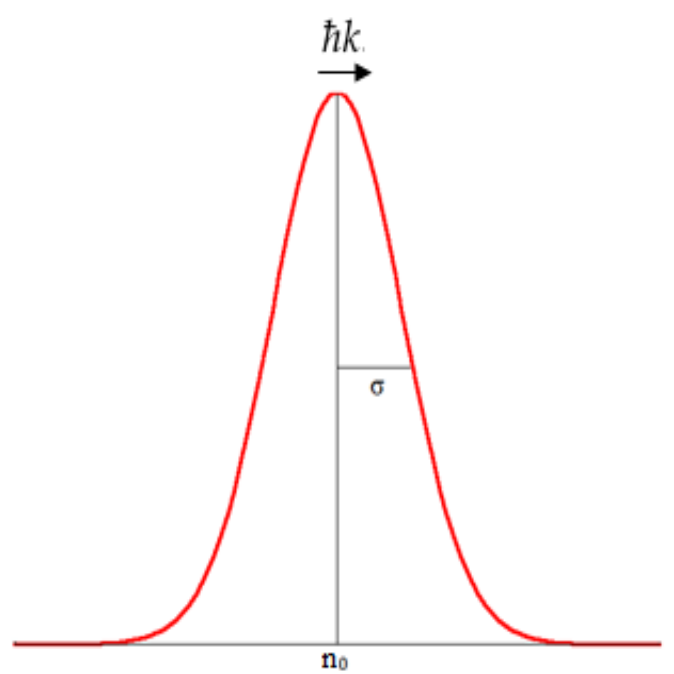

Figura 5 - Representação de um pacote de onda centrado em $n_{0}$ com largura $\sigma$ e momento linear $\hbar k$. 


$$
C_{n}=e^{i k n a} \frac{e^{-\left(n-n_{0}\right)^{2} / 2 \sigma^{2}}}{A}
$$

onde $A$ é o fator de normalização da função de onda.

Para avaliar a dinâmica do pacote de onda, utilizamos algumas medidas como a norma, o centroide, o desvio quadrático médio, a função participação, a probabilidade de retorno e a energia do pacote.

A norma é definida por:

$$
\text { Norma }=\sum\left|C_{n}\right|^{2}
$$

e mostra a probabilidade de encontrar o elétron em algum sítio da rede, devendo retornar 1 em qualquer instante do tempo. Esta medida serve como uma forma de verificar se não há problemas com a simulação.

O centroide é a média ponderada de onde está o pacote de onda e é definido como [12]:

$$
\langle x\rangle=\sum_{n=1}^{N} n\left|C_{n}\right|^{2}
$$

Com o centroide obtém-se a evolução do centro do pacote de onda com tempo. Se $x_{0}=0,\langle x\rangle=0$ no instante inicial.

O desvio quadrático médio mede o quanto o pacote desvia da posição inicial e é dado por:

$$
\left\langle x^{2}\right\rangle=\sum_{n=1}^{N} n^{2}\left|C_{n}\right|^{2}
$$

A variância mostra o quanto o pacote de onda dispersa em relação ao centro do pacote e é dada por:

$$
\sigma^{2}=\left\langle x^{2}\right\rangle-\langle x\rangle^{2}
$$

A função participação mede quantos sítios participam do pacote, sendo representada por:

$$
\text { Participação }=\frac{1}{\sum\left|C_{n}\right|^{4}}
$$


Para verificar que a função participação dá como resultado quantos sítios participam da função de onda, vamos dar como exemplo um rede unidimensional. Suponha que a função de onda esteja distribuida entre 3 sítios: nos sítios 31, 32 e 33, por exemplo - com $\frac{1}{3}$ de chance do elétron estar em cada um desses sítios.

O somatório dessas probabilidades dá:

$$
\sum_{n}\left|C_{n}\right|^{4}=\left(\frac{1}{3}\right)^{2}+\left(\frac{1}{3}\right)^{2}+\left(\frac{1}{3}\right)^{2}=\frac{1}{3}
$$

Como:

$$
\text { Participação }=\frac{1}{\sum\left|C_{n}\right|^{4}}=\frac{1}{\frac{1}{3}}=3
$$

ou seja, a função participação está associada com quantos sítios participam do pacote de onda.

A probabilidade de retorno é a medida da localização do pacote em relação ao seu estado inicial, considerando que os coeficientes são oriundos do estado inicial. E é dada por:

$$
\text { Retorno }=\sum_{n^{*}}\left|C_{n^{*}}\right|^{2}
$$

onde $n^{*}$ são os estados que participam do pacote inicial.

A medida da energia é dada por:

$$
\langle E\rangle=\langle\Psi|\hat{H}| \Psi\rangle
$$

Substituindo as eqs. (1.15) e (1.11) temos:

$$
\begin{gathered}
\langle E\rangle=\sum_{n, n^{\prime}, n^{\prime \prime}} C_{n^{\prime}}^{*}\left\langle n^{\prime}\left|(-W|n+1\rangle\langle n|-W| n\rangle\langle n+1|) C_{n^{\prime \prime}}\right| n^{\prime \prime}\right\rangle \\
\langle E\rangle=-W \sum_{n}\left(C_{n+1}^{*} C_{n}+C_{n}^{*} C_{n+1}\right)
\end{gathered}
$$

A curva na Fig. 6 representa a energia $\langle E\rangle$ em função do $k$ do estado inicial, onde $C_{n}$ é dado pela eq.(1.25) (consideramos $\sigma=5$ ). O resultado obtido numericamente, coincide com o resultado analítico da eq.(1.14). 


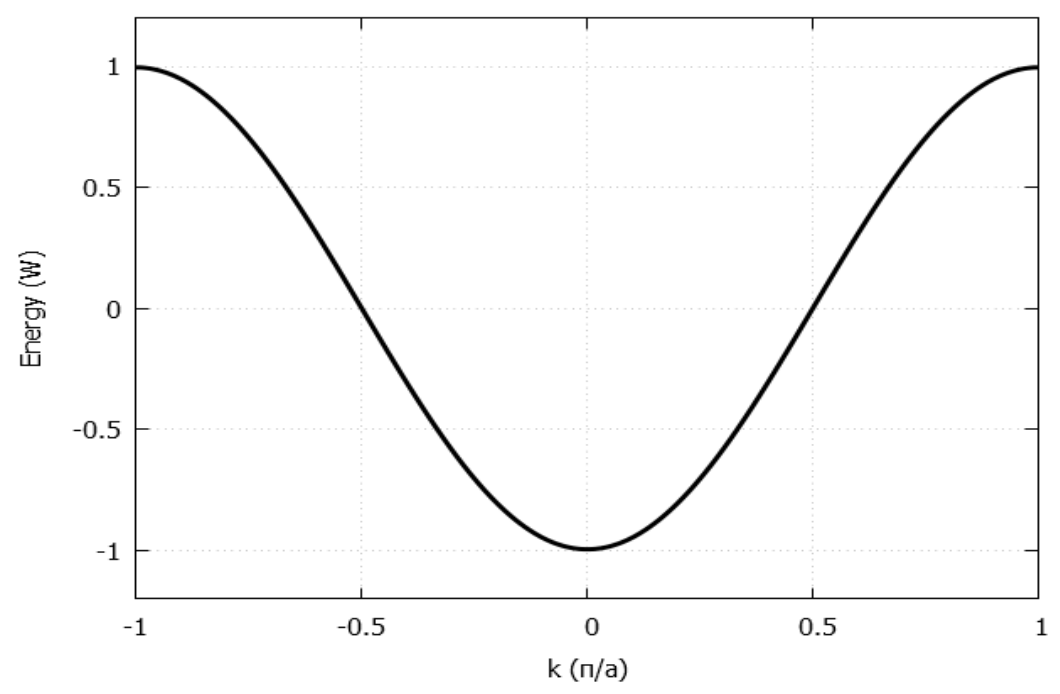

Figura 6 - Relação de Dispersão - Energia em função de $k$

\subsection{Programa}

Apesar do modelo tight-binding ter solução análitica exata, desenvolvemos o programa para fazer análise numérica do comportamento da função de onda no modelo tight-binding.Dessa maneira, o algoritmo desenvolvido será a base para resolver problemas que não tem solução analítica e ao mesmo tempo serve para validar o mesmo.

Para o desenvolvimento do programa utilizamos a linguagem de programação C. Utilizamos rotinas de cáculos númericos fornecidos pela Intel Math Kernel Library (MKL) [13]. Abaixo apresentamos o algoritmo básico utilizado e as suas sub-rotina. 

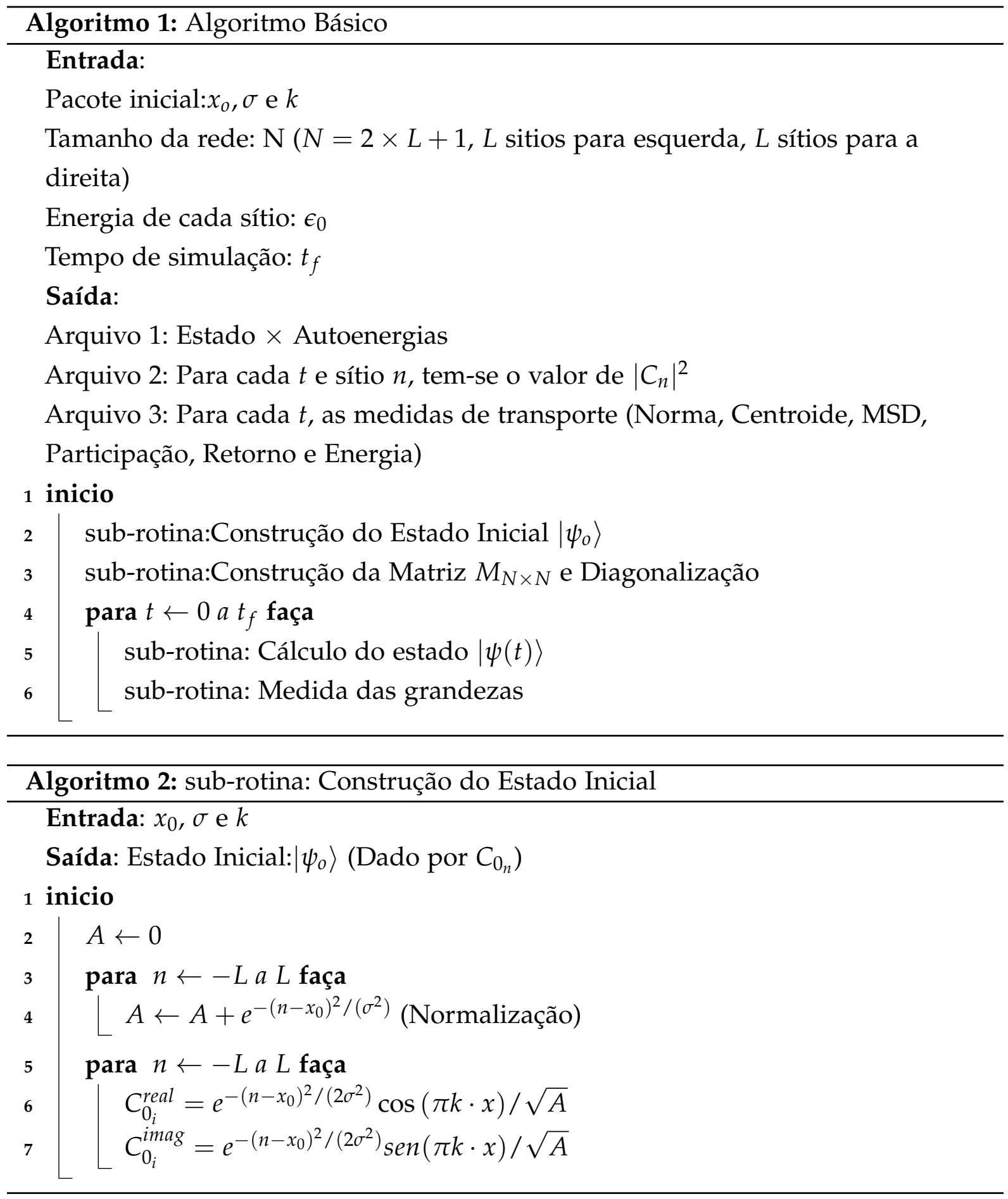

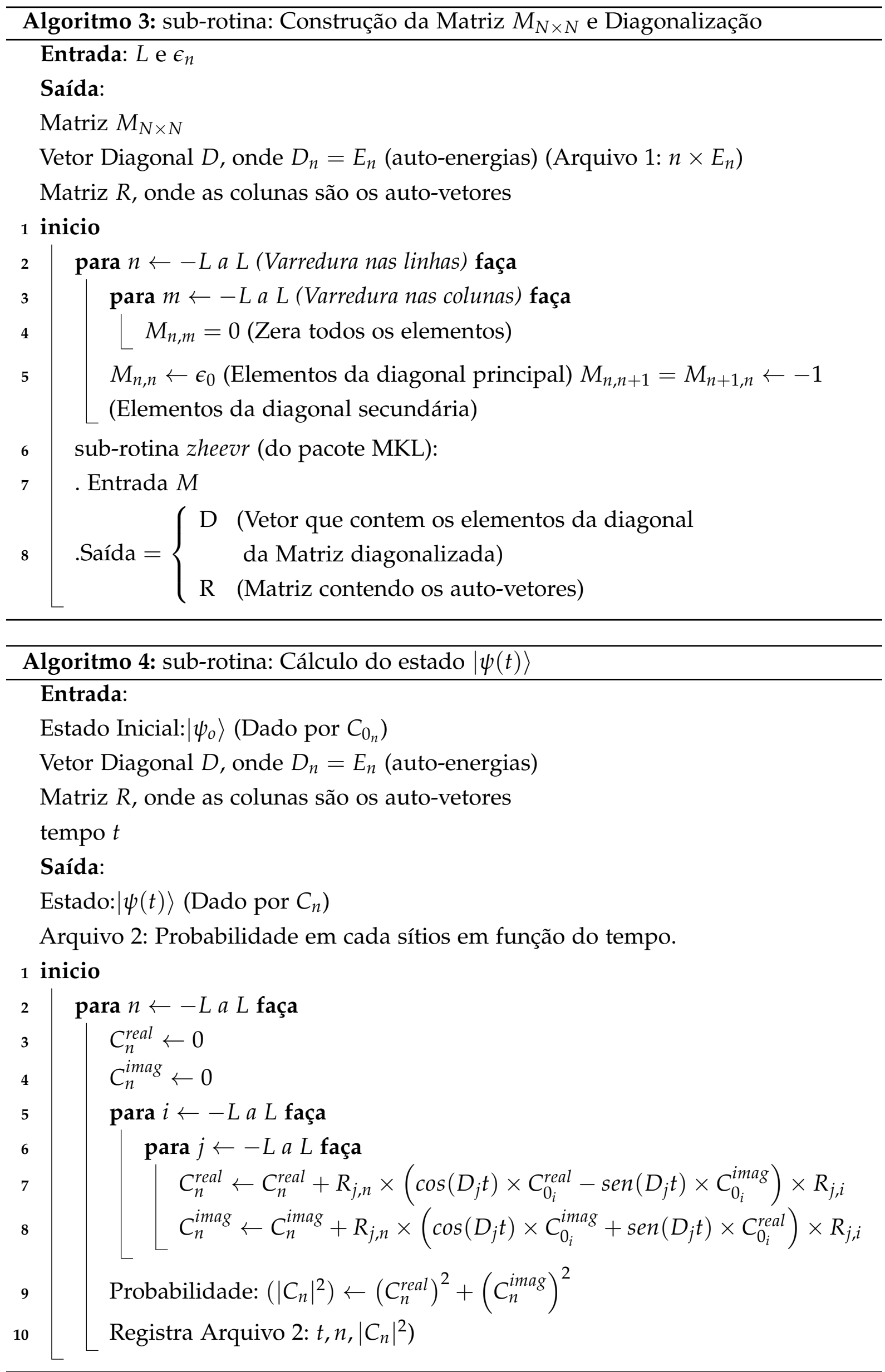


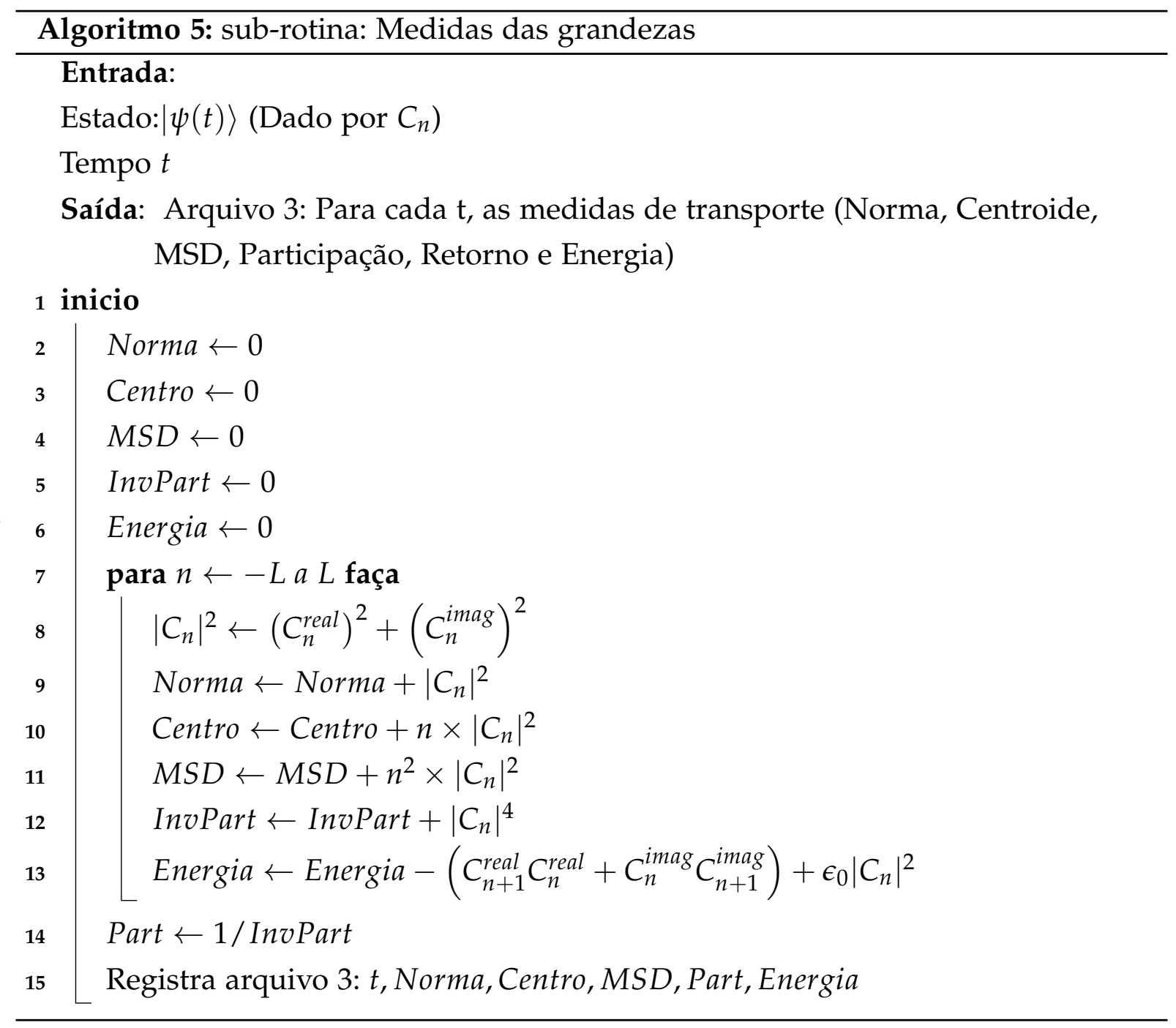

\subsubsection{Análise dos Resultados}

A Fig. 7 mostra a evolução temporal de algumas medidas de transporte obtidas computacionalmente através do algoritmo descrito na seção anterior, para dois casos: momento linear nulo $(k=0.0)$ e não nulo $(k=0.1)$.

Relembremos aqui que, apesar de todas essas grandezas terem resultados análiticos, esta analise utilizando o algoritmo é a base para o estudo das grandezas em hamiltonianos mais complexos.

As unidades de medidas deste trabalho estão descritas na Lista de símbolos (página 10).

Na função Retorno verificamos que conforme esperado, ao dar um valor para $k \neq 0$, a função de onda sai dos sítios que representam o estado inicial mais rápido, já que a probabilidade de retorno cai mais rapidamente. Na função participação é possível observar uma diminuição do número de sítios que participam do pacote de onda, uma vez presente um momento linear inicial $\hbar k \neq 0$. O mesmo se observa na 
variância, o pacote torna-se um pouco menos disperso em torno do centro do pacote quando $(k \neq 0.0)$. Na função centroide, é fácil verificar que ao dar um momento linear ao elétron, ele rapidamente se desloca da sua posição original. Podemos, a partir dos gráficos, concluir que ao dar um valor de $k \neq 0$ para o pacote inical que representa o elétron, temos que a função se desloca da sua posição original, mas com uma menor dispersão em torno do seu centro, ou seja, um número menor de sítios participa da função de onda.
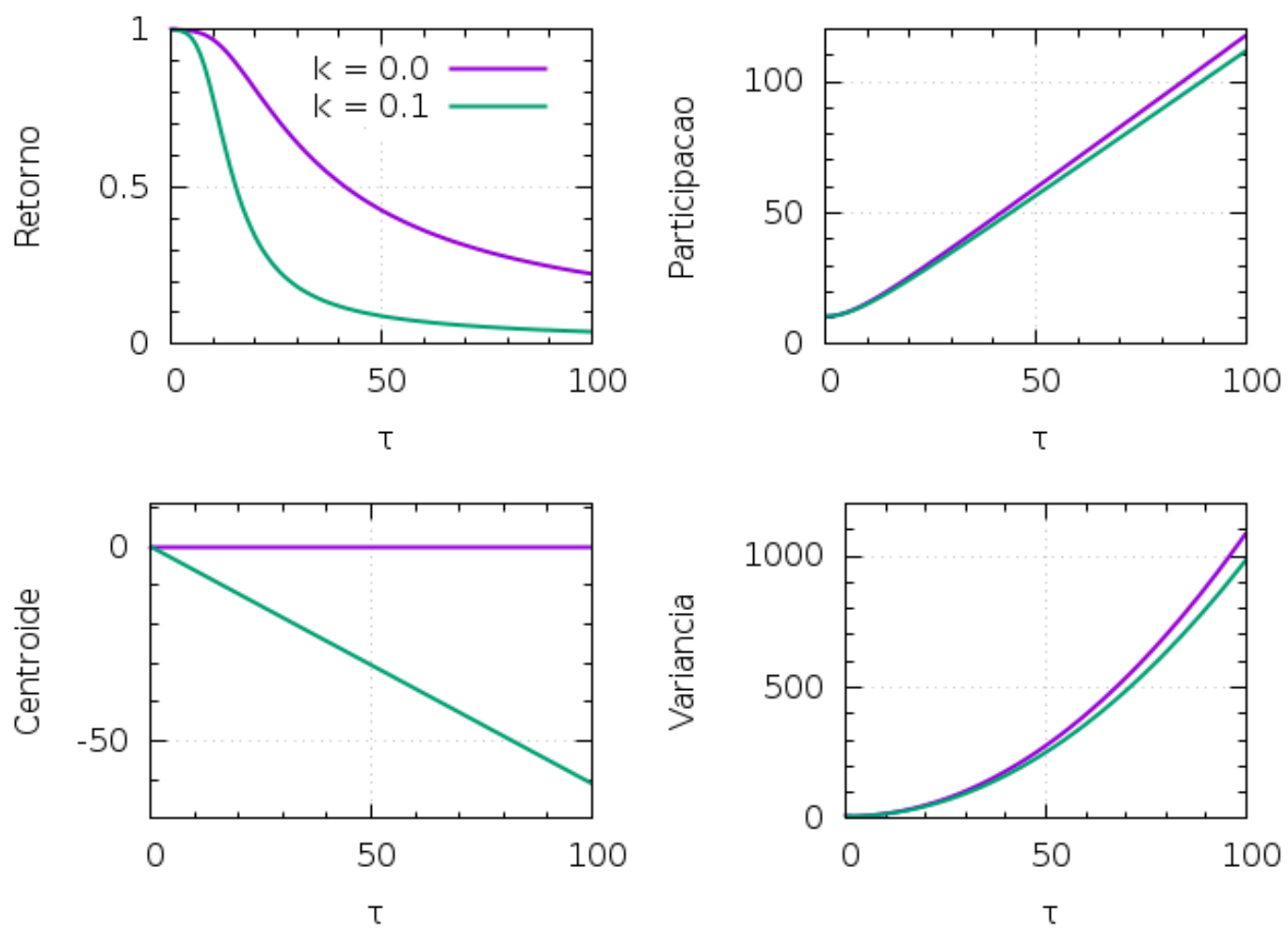

Figura 7 - Evolução temporal da função Probabilidade de retorno, da participação, do centroide e da variância. Para $\sigma=3$, e dois valores de $k(0.0$ e 0.1$)$

Essas conclusões feitas com base nos gráficos da Fig. 7 também podem ser obtidas tendo como referência os gráficos tridimensionais indicados nas Figs. 8 e 9 que mostram a evolução temporal do pacote de onda em forma de uma gaussiana.

Observe que há uma diferença no espalhamento da gaussiana no decorrer do tempo nas Figs. 8 e 9, isso porque o número de sítios que participam do pacote diminuem com a presença de um momento linear inicial. Observe também que ao contrário da Fig. 8 na qual $k=0.0$ da Fig. 9 a gaussiana não fica localizada no centro da rede cristalina no decorrer do tempo, ela desloca para o lado. Isso também está relacionado ao momento linear inicial que foi fornecido. 


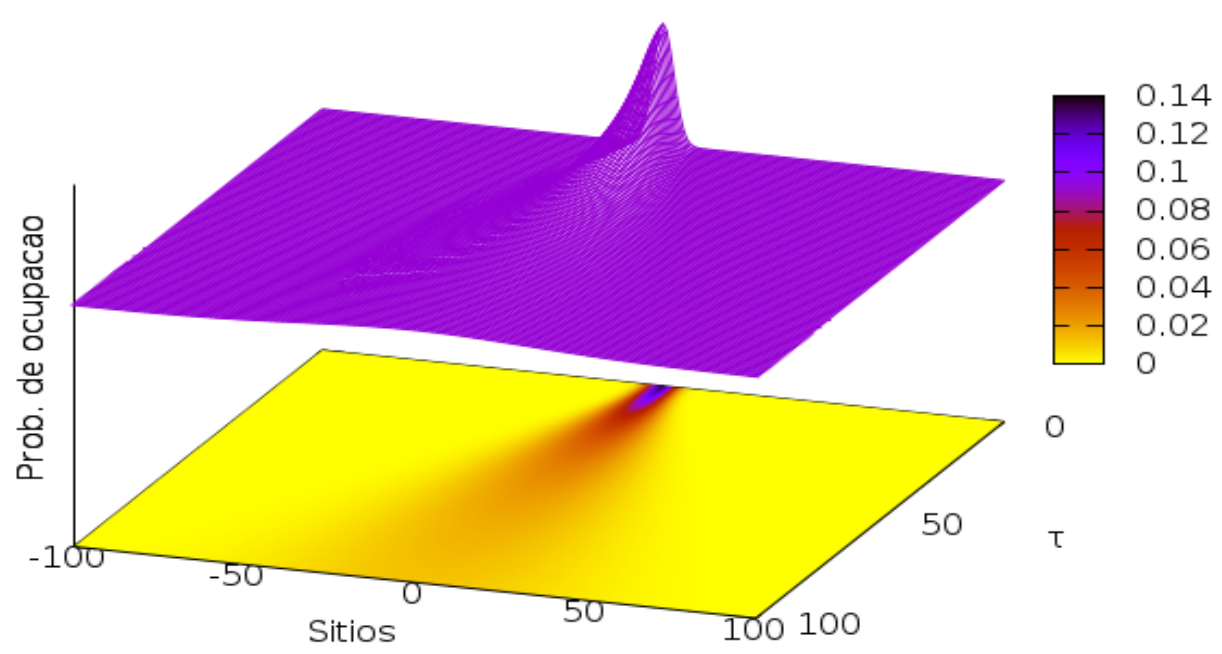

Figura 8 - Evolução temporal do pacote, $\operatorname{com} \sigma=3$ e $k=0.0$

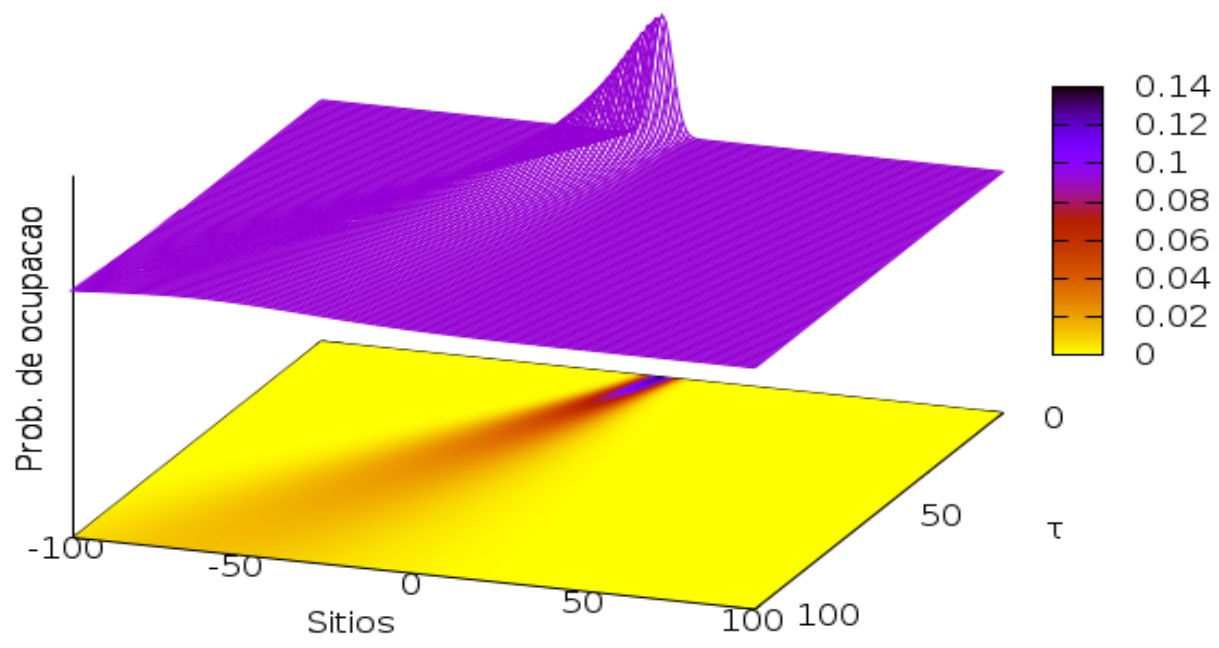

Figura 9 - Evolução temporal do pacote , $\operatorname{com} \sigma=3$ e $\mathrm{k}=0.1$

Na Fig. 10, é possível observar que a medida que o valor de $k$ aumenta, com base no gráfico do retorno o pacote de onda fica menos localizado no decorrer do tempo, o pacote "sai"rapidamente do seu estado inicial. O número de sítios que participam do pacote diminuem com o aumento de $k$ e a variância também diminuiu. 
Fixando o valor de $k=0.1$ e variando o $\sigma$, a análise dos gráficos do retorno e da participação na Fig. 11 mostra que a medida que $\sigma$ aumenta o pacote fica mais localizado, espalha menos e consequentemente há uma menor participação no número de sítios. A explicação para isso é que quanto maior $\sigma$, maior será a precisão do momento, pois $\Delta x \Delta k>1$ [14]. Se $\Delta x$ aumenta, $\Delta k$ diminui, fazendo com que o pacote se disperse mais devagar.
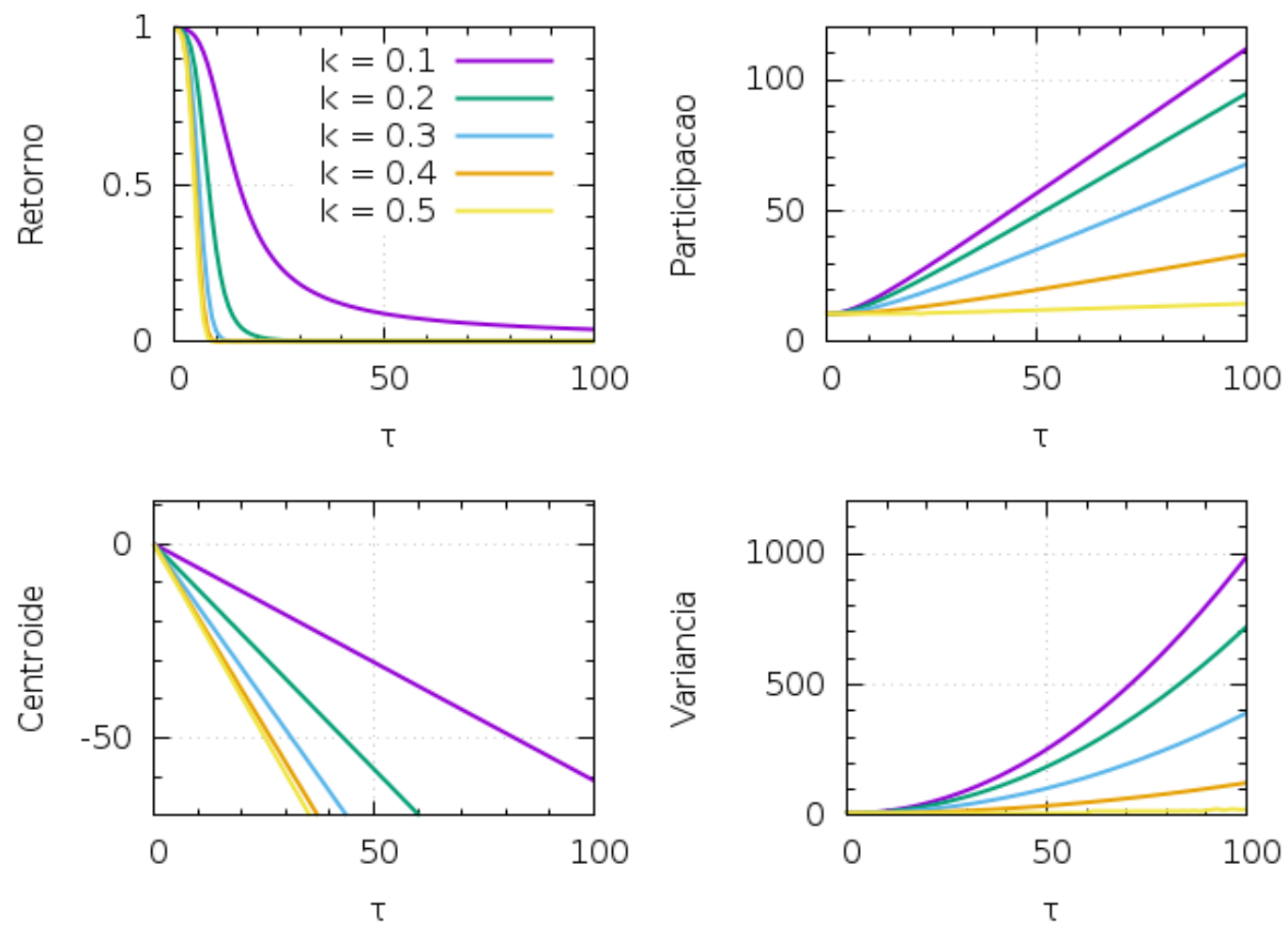

Figura 10 - Evolução temporal da função retorno, da participação, do centroide e da variância. $\operatorname{Com} \sigma=3$ e k variando entre 0.1 a 0.5

Esaas medidas de transporte nos permitem fazer uma análise comparativa mais eficiente, sem necessidade de recorrer a visualização do pacote como um todo, como fizemos nas figuras em 3D. 

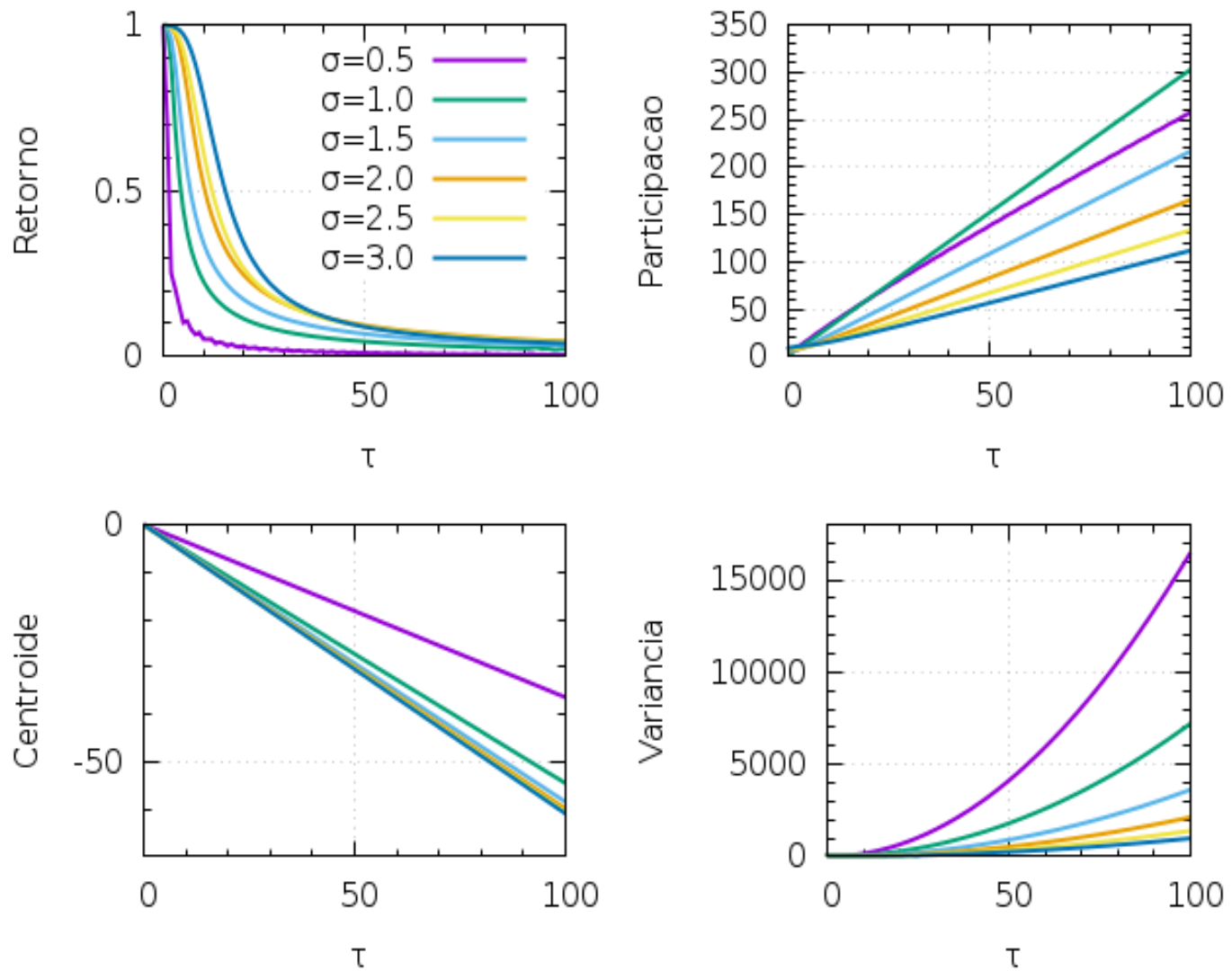

Figura 11 - Evolução temporal do retorno, da participação, do centroide e da variância. Com $\sigma$ variando entre 0.5 a 3.0 , e $\mathrm{k}=0.1$

Neste capítulo estudamos o modelo tight binding, analisando a relação de dispersão e o comportamento dinâmico do elétron (representado por um pacote gaussiano). No próximo capítulo, o hamiltoniano sofrerá um acréscimo devido a interação spinórbita e a modulação externa provininente de nano-capacitores depositados sobre o material. 


\section{Modelo de um fio quântico com intera- ções Spin-órbita submetido a um campo elétrico modulado}

Neste capítulo mostraremos o modelo que se deseja analisar bem como a interpretação física de cada termo do hamiltoniano que representa o sistema.

O hamiltoniano completo envolve a soma de vários termos:

$$
H=H_{0}+H_{D R}+H_{M O D}
$$

Nas seções seguintes veremos em detalhes o significado desses termos.

\subsection{Hamiltoniano de elétrons não interagentes}

O termo $H_{0}$, é dado pelo hamiltoniano tight-binding estudado no capítulo anterior.

$$
H_{0}=-W \sum_{n, \sigma}(|n, \sigma\rangle\langle n+1, \sigma|+| n+1, \sigma\rangle\langle n, \sigma|)-\mu \sum_{n, \sigma}|n, \sigma\rangle\langle n, \sigma|
$$

onde $W$ é a amplitude de hopping e o $\mu$ é o potencial químico e o $\sigma=\uparrow, \downarrow$ a orientação do spin do elétron com relação a um eixo de quantização.

\subsection{Interação Spin-órbita Dresselhaus e Rashba}

As interações Dresselhaus e Rashba descrevem interações do tipo spin-órbita. A dedução do hamiltoniano pode ser entendida com mais detalhes em [15].

\subsubsection{Interação Spin-órbita}

A origem física da interação spin-órbita vem da interação entre o movimento do elétron em torno do núcleo e o seu spin. Os elétrons possuem momento angular intrínseco, o spin, e este está associado a um momento de dipolo magnético de spin.

A interação spin-órbita em átomos isolados vem da energia de interação do momento de dipolo magnético de spin com o campo magnético gerado pelo núcleo. 
Numa análise clássica podemos considerar, tendo o elétron como referencial, que o próton realiza uma órbita circular em torno do elétron, e isso gera um campo magnético $B$ [16, p. 202]. O campo gerado por uma corrente $i$, em uma espira de raio $R$, gera um campo magnético que é dado por:

$$
\boldsymbol{B}=\frac{\mu_{0} i}{2 R}
$$

onde $i$ é dado por:

$$
i=\frac{e}{T}
$$

onde $e$ é a carga do elétron, e $T$ é o período da órbita.

Assim temos que:

$$
\boldsymbol{B}=\frac{\mu_{0} e}{2 R T}
$$

onde $\mu_{0}$ é a constante de permeabilidade do vácuo.

A energia da interação spin-órbita pode ser escrita como:

$$
H_{S O}=-\boldsymbol{\mu}_{S} \cdot \boldsymbol{B}
$$

onde $\boldsymbol{B}$ é o campo magnético do núcleo no referencial do elétron e $\boldsymbol{\mu}_{S}=\frac{-e}{m_{e}} S$ representa o momento magnetico e $S$ momento angular de spin do elétron.

\subsubsection{Hamiltoniano Dresselhaus e Rashba}

O movimento relativo do próton em torno do elétron é devido a interação colombiana. Devido a simetria da estrutura cristalina, o campo magnético gerado por esse movimento se anula. Isso significa que somente haverá campo se houver uma falta de simetria, o que dá origem a interação spin-órbita do tipo Dresselhaus, tal efeito ocorre em alguns semicondutores.

A quebra de simetria pode ser ocasionada também por um campo externo, a interação Rashba surge devido a quebra de simetria na interface entre dois materiais semicondutores diferentes. Quando são colocados dois semicondutores de materiais diferentes em contato, os elétrons mais externos presente nos materiais semicondutores 
tendem a ir para interface formando um poço quântico onde os elétrons ficam confinados energeticamente. Na superfície de contato entre os dois materiais semicondutores ocorre o aparecimento um campo elétrico indo na direção de um material para o outro em virtude da diferente composição química dos dois materiais dando origem a uma quebra de simetria, que dá origem a interação Rashba.

Utilizando a base $|n, \sigma\rangle$, a interação Dresselhaus [17] é dada por:

$$
H_{D}=-i \sum \gamma_{D} \sigma^{x}\left(|n, \sigma\rangle\left\langle n+1, \sigma^{\prime}|+| n+1, \sigma\right\rangle\left\langle n, \sigma^{\prime}\right|\right)
$$

e a interação Rashba [18] é dada por:

$$
H_{R}=-i \sum \gamma_{R} \sigma^{y}\left(|n, \sigma\rangle\left\langle n+1, \sigma^{\prime}|+| n+1, \sigma\right\rangle\left\langle n, \sigma^{\prime}\right|\right)
$$

onde $\sigma^{x}$ e $\sigma^{y}$ são as matrizes de Pauli e $\gamma_{R}$ e $\gamma_{D}$ representam as intensidades das interações spin-orbita Rashba e Dresselhaus, respectivamente.

Como no espaço dos spins o hamiltoniano não esta diagonalizado, faz-se necessário uma rotação nesse espaço. Detalhes de tal transformação podem ser vistos no trabalho de Malard. et. al. [5]

Após essa rotação a interação conjunta $H_{D R}=H_{D}+H_{R}$ é dada por:

$$
H_{D R}=-i \gamma_{e f f} \sum_{n, \tau} \tau(|n, \tau\rangle\langle n+1, \tau|+| n+1, \tau\rangle\langle n, \tau|)
$$

sendo que $\tau$ vale 1 (spin $u p$ ) ou -1 (spin down), e $\gamma_{\text {eff }}=\sqrt{\gamma_{R}^{2}+\gamma_{D}^{2}}$

Os outros termos do hamiltoniano também utilizarão desta nova base com spins rotacionados.

\subsection{Interação com modulação}

Suponha que um fio quântico é modelado em uma heteroestrutura em cima da qual é colocada uma sequência periódica de eletrodos em nanoescala de igual tamanho, carregados positivamente e separados pela mesma distância ao longo da direção do fio, como ilustrado na Fig. 12. Quando são carregadas, se produz uma modulação periódica do acoplamento Rashba, juntamente com uma modulação do potencial químico local no fio. A modulação será suavemente variada ao longo do fio, o que reflete a extensão finita dos eletrodos [5]. 


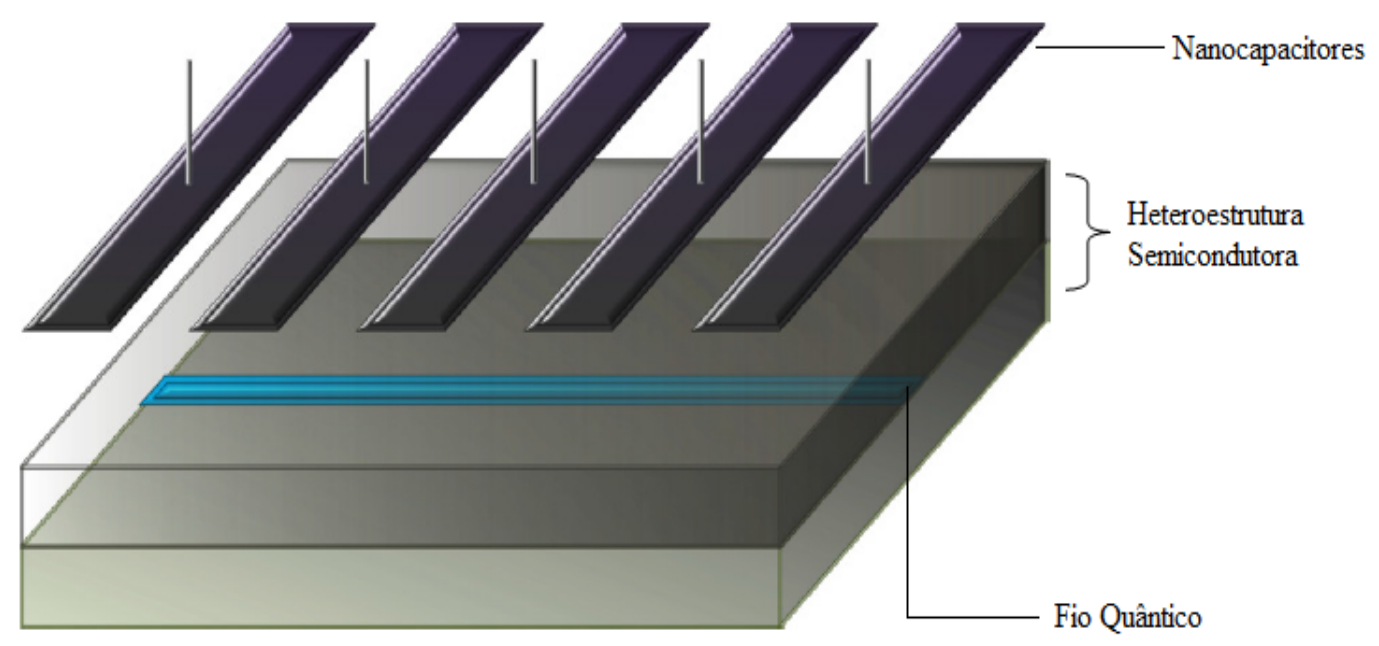

Figura 12 - Capacitores acoplados em um fio quântico sobre uma heteroestrutura. Fonte: Malard et. al. [19]

A Fig. 12 representa o dispositivo proposto por Malard. et. al. [19] e para uma boa aproximação, a modulação pode ser representada por um harmônico simples (função senoidal).

No hamiltoniano modulado estão presentes o potencial químico modulado $\mu(n)$ e a interação do tipo Rashba $\gamma_{R}(n)$ que é sensível ao campo externo.

$$
\begin{aligned}
H_{\text {mod }}= & -i \sum_{n, \tau} \gamma_{R}(n) \tau \cos (2 \theta)|n, \tau\rangle\langle n+1, \tau|+| n, \tau\rangle\langle n+1, \tau| \\
& +i \sum_{n, \tau} \gamma_{R}(n) \operatorname{sen}(2 \theta)|n, \tau\rangle\langle n+1,-\tau|+| n, \tau\rangle\langle n+1,-\tau| \\
& -\frac{1}{2} \sum_{n, \tau} \mu(n)|n, \tau\rangle\langle n, \tau|+| n, \tau\rangle\langle n, \tau|
\end{aligned}
$$

$\operatorname{com} \gamma_{R}(n) \equiv \gamma_{R_{\text {mod }}} \cos (q n a), \mu(n) \equiv \mu_{\text {mod }} \cos (q n a)$, onde $q$ representa o número de onda da modulação externa e o $\theta=\arctan \left(\gamma_{D} / \gamma_{R}\right)$

Tomando $\mu_{\text {mod }}>0$, o acoplamento Rashba e o potencial químico modulado estão "em fase" quando $\gamma_{R_{\text {mod }}}>0$, enquanto que para $\gamma_{R_{\text {mod }}}<0$ as duas modulações estão fora de fase por $\pi$ [5]. 


\subsection{Notação Matricial}

De forma similar aos passos realizados no capítulo 1, foi adicionado o spin e o estado inicial $\Psi_{0}$ agora é dado por:

$$
\left|\Psi_{0}\right\rangle=\sum_{n, \tau} C_{n, \tau}|n, \tau\rangle
$$

onde $\left|C_{n, \tau}\right|^{2}$ é a probabilidade de encontrar o elétron no sítio $n \operatorname{com} \operatorname{spin} \tau$.

Como o elétron pode estar com o spin down ou up, temos que a Norma $a_{\downarrow}$ é a probabilidade de encontrar o elétron com spin down:

$$
\text { Norma }_{\downarrow}=\sum_{n}\left|C_{n,+1}\right|^{2}
$$

e a $\operatorname{Norma}_{\uparrow}$ é a probabilidade de encontrar o elétron com spin up:

$$
\operatorname{Norma}_{\uparrow}=\sum_{n}\left|C_{n,-1}\right|^{2}
$$

onde a soma das duas probabilidades é igual a 1:

$$
\operatorname{Norma}_{\downarrow}+\operatorname{Norma}_{\uparrow}=1
$$

Para representar o novo estado $|n, \tau\rangle$, iremos utilizar de um vetor $\vec{f}$ com o dobro do tamanho $(2 N)$ tal que:

$$
\vec{f}=\left(\begin{array}{c}
C_{1} \\
C_{2} \\
C_{3} \\
\vdots \\
C_{N} \\
\vdots \\
C_{N+1} \\
C_{N+2} \\
\vdots \\
C_{2 N}
\end{array}\right)
$$


sendo que $C_{1}$ até $C_{N}$ representa o elétron com spin down e do vetor $C_{N+1}$ ate $C_{2 N}$ representa o elétron com spin $u p$.

A equação de Schrödinger escrita em forma de matriz, como mostra a equação 1.19 é:

$$
i \hbar \frac{\partial}{\partial t} \vec{f}=M \vec{f}
$$

Como $H$ é a soma dos três hamiltonianos $H_{0}, H_{D R}, H_{M O D}$, a matriz $M$ não é uma matriz real e sim uma matriz complexa hermitiana (matriz conjugada transposta igual a ela mesma).

Como o tamanho do vetor função de onda foi duplicado, temos que o hamiltoniano também será dobrado. Podemos assim escrever a matriz $M$ como:

$$
M_{2 N, 2 N}=\left(\begin{array}{ll}
M_{N, N}^{-,-} & M_{N, N}^{-,+} \\
M_{N, N}^{+,-} & M_{N, N}^{+,+}
\end{array}\right)
$$

onde:

$$
M^{\tau, \tau}=\left(\begin{array}{ccccc}
\Lambda_{1} & \xi_{1} & 0 & 0 & \cdots \\
\xi_{1}^{*} & \Lambda_{2} & \xi_{2} & 0 & \cdots \\
0 & \xi_{2}^{*} & \Lambda_{3} & \xi_{3} & \cdots \\
0 & 0 & \xi_{3}^{*} & \Lambda_{4} & \cdots \\
\vdots & \vdots & \vdots & \vdots & \ddots
\end{array}\right)
$$

$\operatorname{com} \Lambda_{n}$ e $\xi_{n}$ dados por:

$$
\begin{gathered}
\Lambda_{n}=\mu+\mu_{\text {mod }} \cos (\pi n q) / 2 \\
\xi_{n}=W+i \tau\left(\gamma_{e f f}+\gamma_{\text {mod }} \cos (2 \theta) \cos (\pi n q)\right)
\end{gathered}
$$


E temos a matriz da diagonal secundária com troca de spin:

$$
M^{\tau,-\tau}=\left(\begin{array}{ccccc}
0 & \varsigma_{1} & 0 & 0 & \cdots \\
\varsigma_{1}^{*} & 0 & \varsigma_{2} & 0 & \cdots \\
0 & \varsigma_{2}^{*} & 0 & \varsigma_{3} & \cdots \\
0 & 0 & \varsigma_{3}^{*} & 0 & \cdots \\
\vdots & \vdots & \vdots & \vdots & \ddots
\end{array}\right)
$$

onde $\varsigma_{n}$ é dado por:

$$
\zeta_{n}=i \gamma_{\bmod } \operatorname{sen}(2 \theta) \cos (\pi n q)
$$

\subsubsection{Medidas de Transporte}

As medidas de transporte abordadas no Capítulo 1 serão reescritas neste capítulo, devido a influência da interação spin-órbita e da modulação externa.

O centroide para elétron com spin down é dado por:

$$
\langle x\rangle_{\downarrow}=\sum_{n=1}^{N} n\left|C_{n}\right|^{2}
$$

e para spin up:

$$
\langle x\rangle_{\uparrow}=\sum_{n=N+1}^{2 N}(n-N)\left|C_{n}\right|^{2}
$$

O desvio quadrático médio com spin down é dado por:

$$
\left\langle x^{2}\right\rangle_{\downarrow}=\sum_{n=1}^{N} n^{2}\left|C_{n}\right|^{2}
$$

com spin up por:

$$
\left\langle x^{2}\right\rangle_{\uparrow}=\sum_{n=N+1}^{2 N}(n-N)^{2}\left|C_{n}\right|^{2}
$$

A variância é dada por:

$$
\sigma_{\tau}^{2}=\left\langle x^{2}\right\rangle_{\tau}-\langle x\rangle_{\tau}^{2}
$$


$\operatorname{com} \tau=-1$ para spin down $\mathrm{e}+1$ para spin $u p$.

A função participação é dada por:

$$
\text { Participação }=\frac{1}{\sum_{n=1}^{2 N}\left|C_{n}\right|^{4}}
$$

A probabilidade de retorno é dado por:

$$
\text { Retorno }_{\tau_{0}}=\sum_{n^{*}}\left|C_{n^{*}}\right|^{2}
$$

onde $n^{*}$ são os estados que participam do pacote inicial, $\tau_{0}$ corresponde ao spin do estado inicial.

$$
\text { Retorno }_{-\tau_{0}}=\sum_{n^{\prime \prime}}\left|C_{n^{\prime \prime}}\right|^{2}
$$

onde $n^{\prime \prime}$ esta situado na mesma região dos sítios mas com spin oposto.

Para o cálculo das energias teremos:

$$
\begin{gathered}
\left\langle E_{0}\right\rangle=\left\langle\Psi\left|\hat{H}_{0}\right| \Psi\right\rangle \\
\left\langle E_{D R}\right\rangle=\left\langle\Psi\left|\hat{H}_{D R}\right| \Psi\right\rangle \\
\left\langle E_{\text {mod }}\right\rangle=\left\langle\Psi\left|\hat{H}_{\text {mod }}\right| \Psi\right\rangle
\end{gathered}
$$

Utilizando das eqs. (2.2) e (2.12), após alguns cálculos, podemos reescrever a eq. (2.28) da seguinte forma:

$$
\left\langle E_{0}\right\rangle=-\sum_{n, \tau}\left(\Re\left(C_{n, \tau}\right) \Re\left(C_{n+1, \tau}\right) \Im+\Im\left(C_{n, \tau}\right) \Im\left(C_{n+1, \tau}\right)+\mu\left|C_{n}\right|_{2}\right)
$$

De forma similar, a partir das eqs. (2.10) e (2.12) podemos reescrever a eq. (2.29):

$$
\left\langle E_{D R}\right\rangle=-\gamma_{e f f} \sum\left(\Re\left(C_{n, \tau}\right) \Im\left(C_{n+1, \tau}\right)-\Re\left(C_{n, \tau}\right) \Im\left(C_{n+1, \tau}\right)\right)
$$

e para parte modulada, a partir das eqs. (2.11) e (2.12) temos: 


$$
\begin{aligned}
\left\langle E_{\text {mod }}\right\rangle= & -\sum_{n} \tau \gamma_{\text {mod }} \cos (q n a) \cos (2 \theta)\left(\Re\left(C_{n, \tau}\right) \Im\left(C_{n+1, \tau}\right)-\Im\left(C_{n, \tau}\right) \Re\left(C_{n+1, \tau}\right)\right) \\
& +\sum_{n} \gamma_{\text {mod }} \cos (q n a) \operatorname{sen}(2 \theta)\left(\Re\left(C_{n, \tau}\right) \Im\left(C_{n+1,-\tau}\right)-\Im\left(C_{n, \tau}\right) \Re\left(C_{n+1,-\tau}\right)\right) \\
& -\frac{1}{2} \sum_{n} \mu_{\text {mod }} \cos (q n a)\left|C_{n, \tau}\right|^{2}
\end{aligned}
$$




\subsection{Algoritmo}

O algoritmo básico foi reescrito, sendo que foi adcionado a interação spin-órbita e a modulação externa.
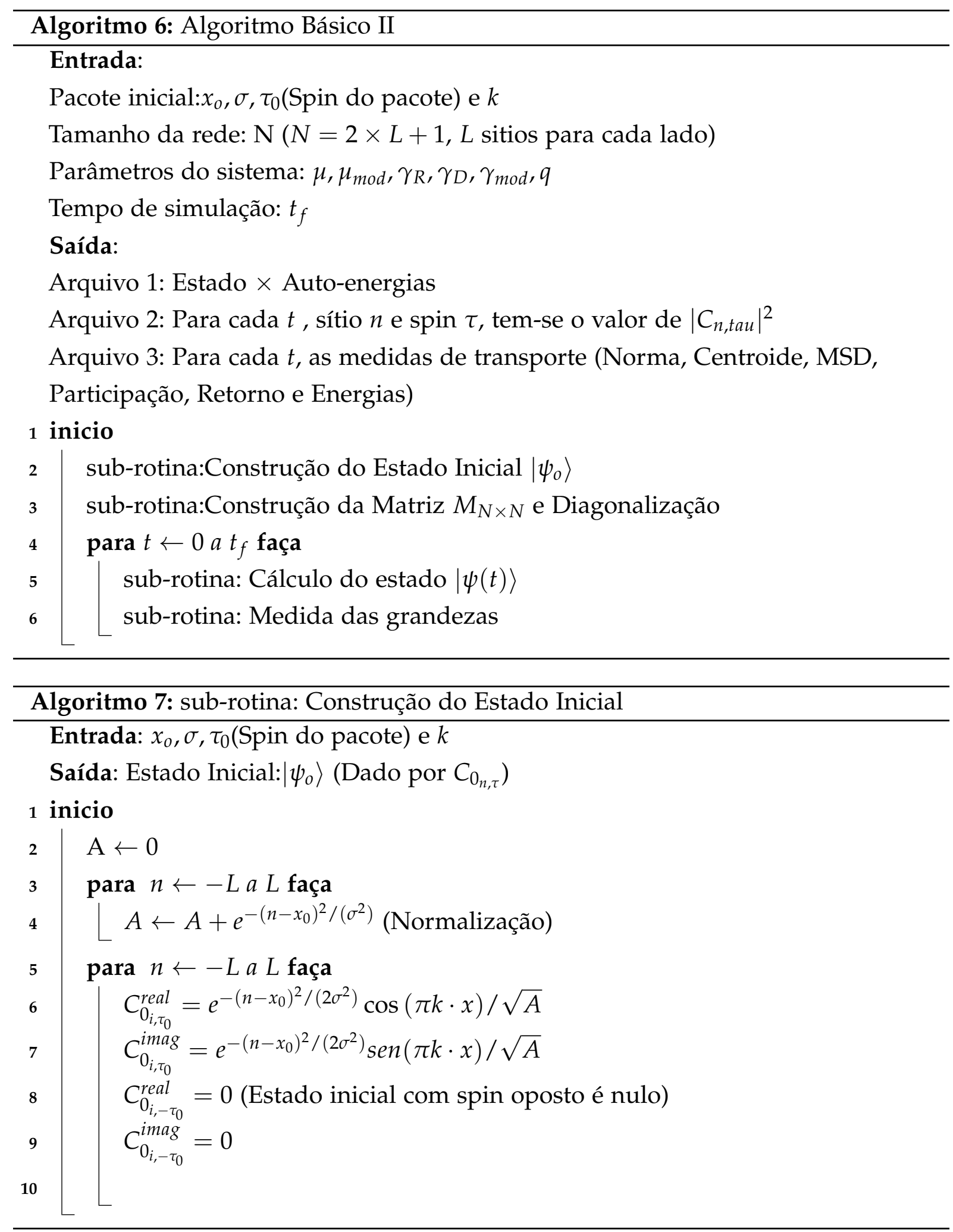


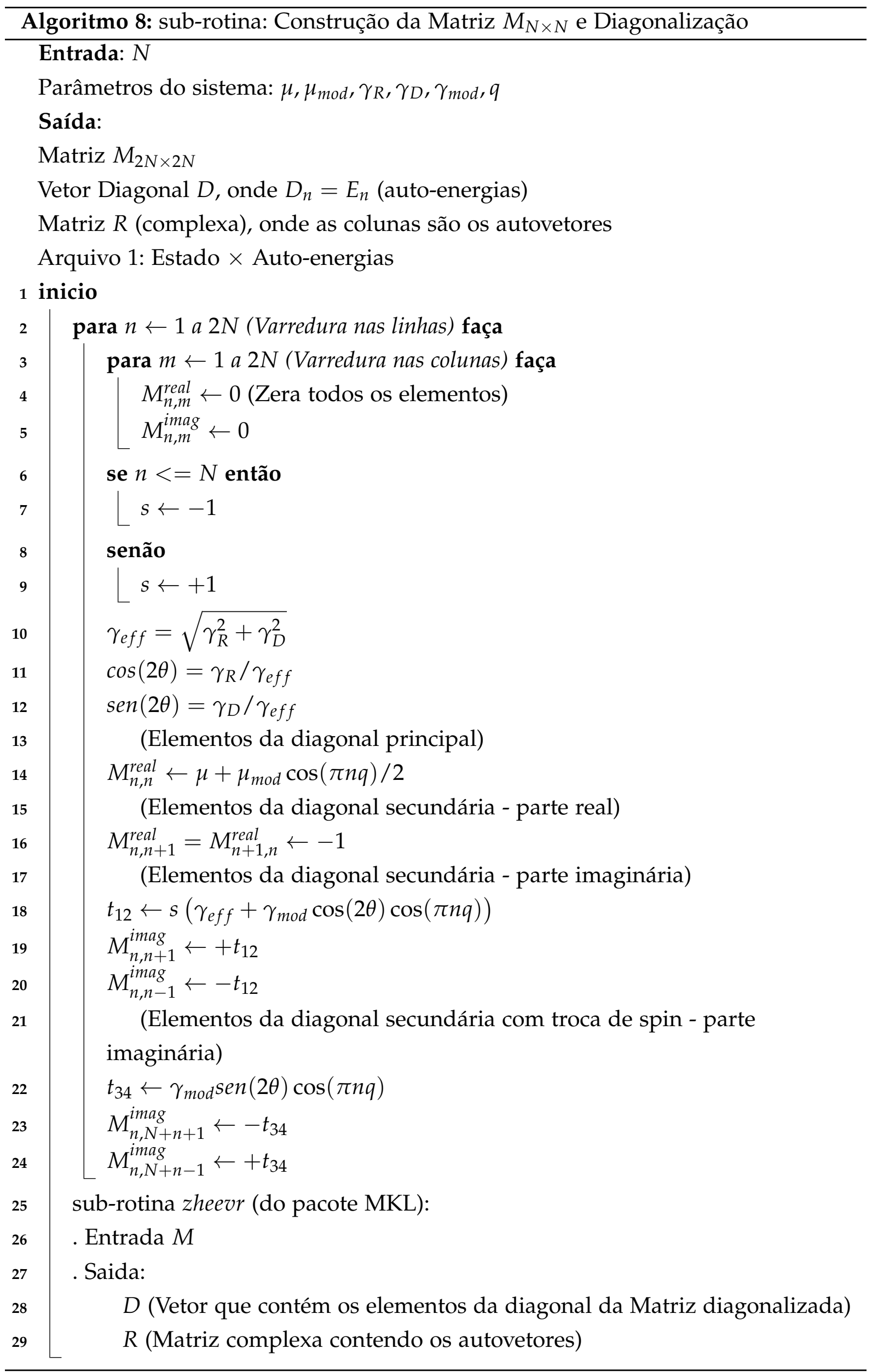




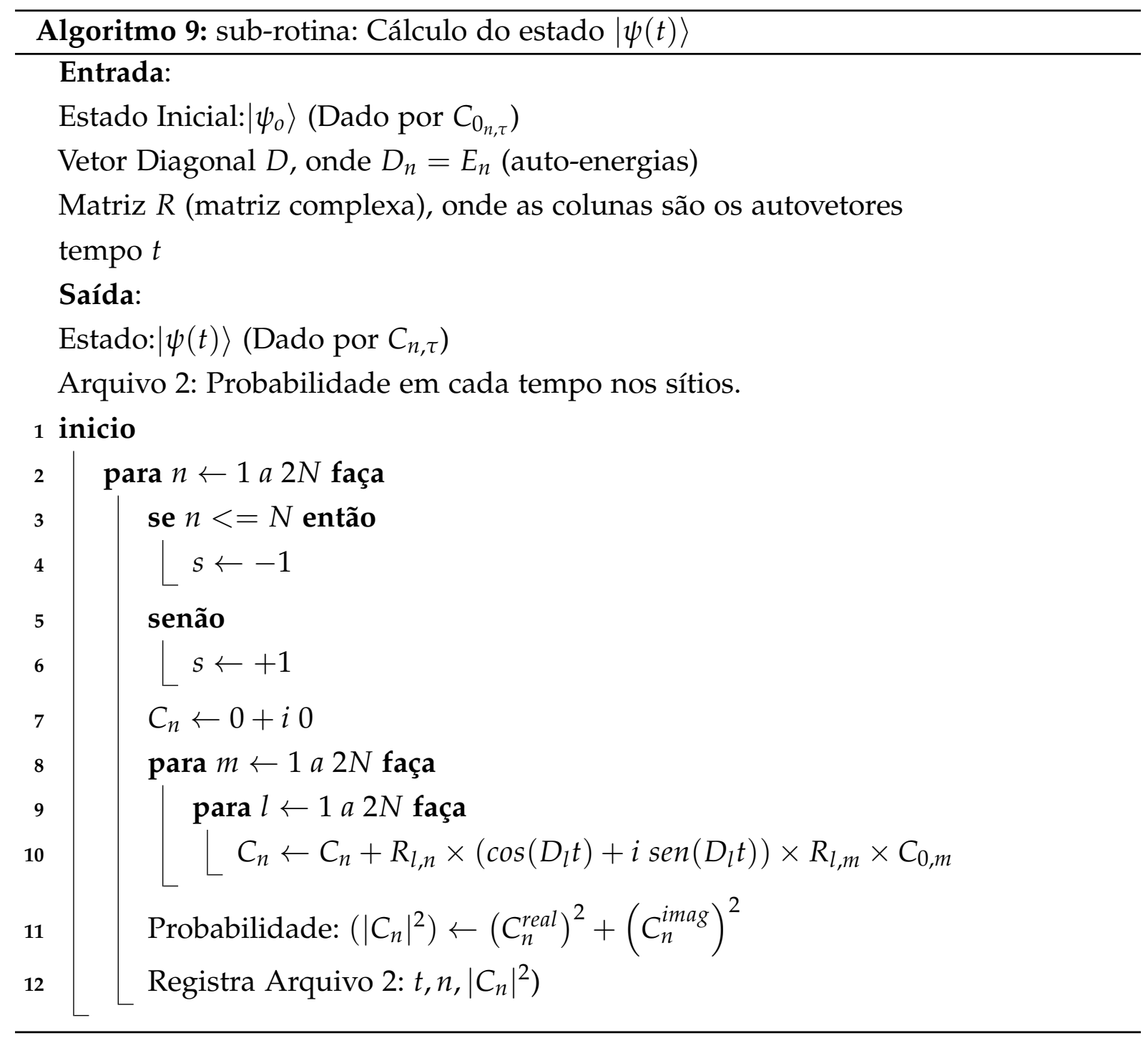




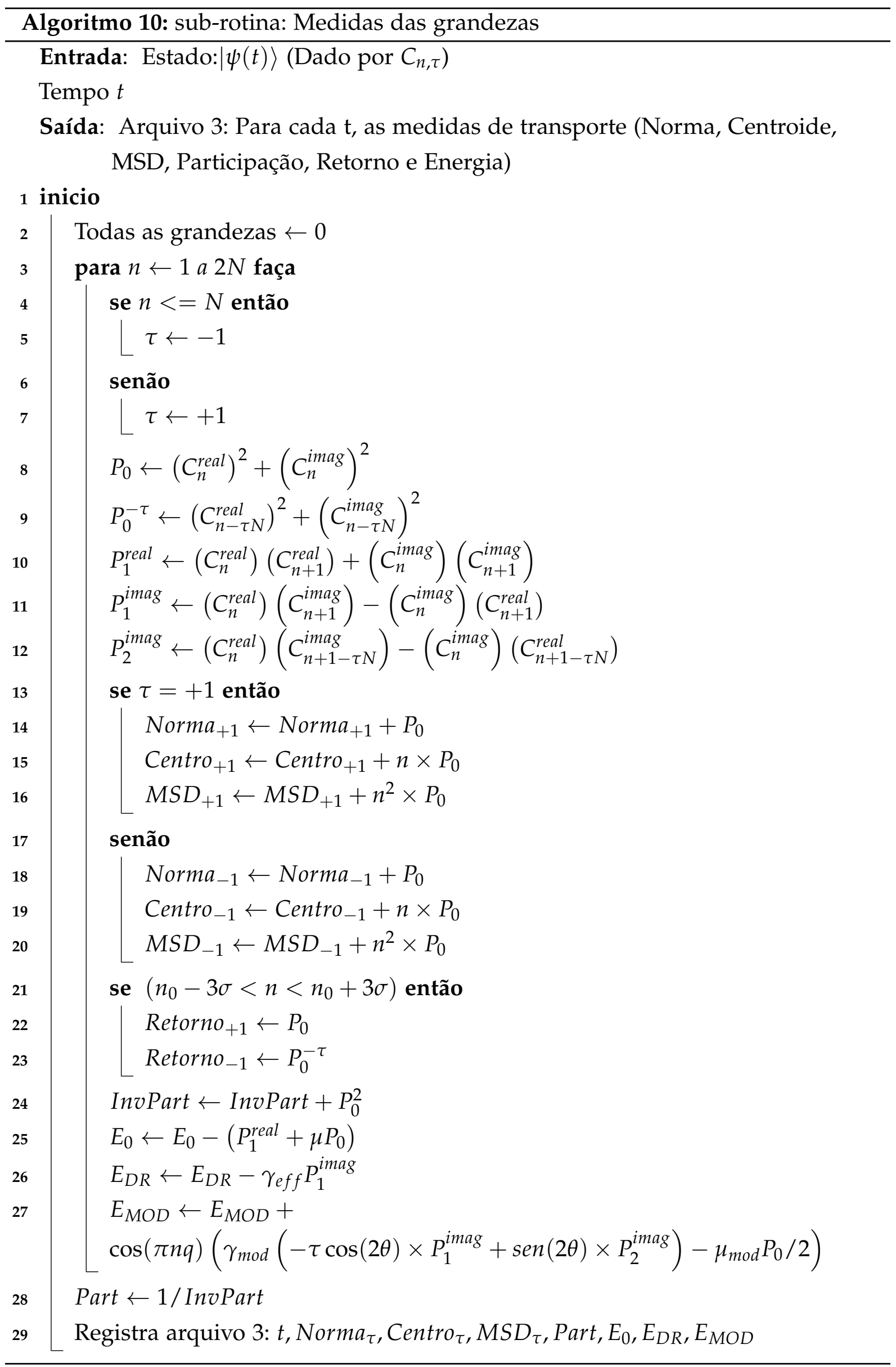




\subsection{Bandas de Energia}

Com base nas autoenergias e autoestados obtidos através do processo diagonalização de matriz, foi possível constuir a estrutura de bandas do sistema estudado. Mostraremos a influência de cada termo do hamiltoniano modulado e o surgimento de gaps na estutura. Detalhes sobre a análise das autoenergias pode ser visto em [15].

Variações no valor de $q$ alteram o número de bandas e onde os gaps aparecem como mostra a Fig. 13. Se $q$ for um número racional, o número de bandas é determinado pelo denominador. Os coeficientes $\gamma_{R}(n)$ e $\mu(n)$ influenciam no tamanho dos gaps. Quando as duas modulações $\gamma_{R}(n)$ e $\mu(n)$ estão em fase eles trabalham em conjunto e aumentam o tamanho do gap, mas, quando estão fora de fase o tamanho do gap diminui, mas nunca chega a zero.
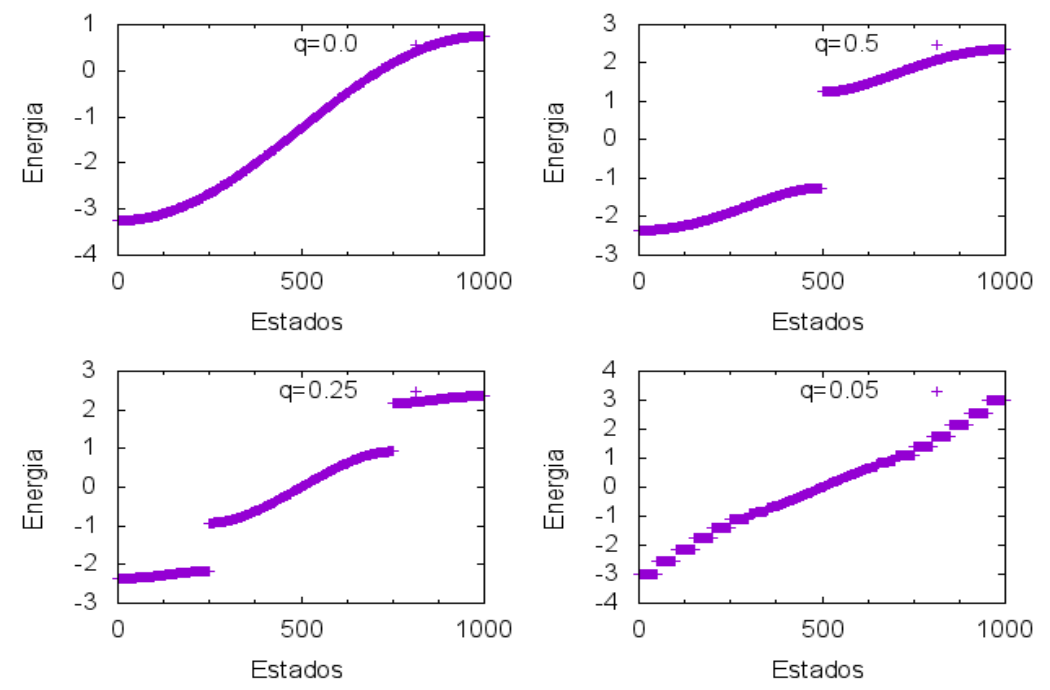

Figura 13 - O número de onda da modulação externa variando em 0.0, 0.25 e 0.5, e o valor da $\mu_{\text {mod }}=2.0$.

O comportamento dinâmico do elétron pode ser entendido muitas vezes analisando o que acontece com os níveis energéticos do sistema. No próximo capítulo será estudado como algumas grandezas se comportam no decorrer do tempo. 


\section{Propriedades de Transporte}

Neste capítulo serão abordadas as propriedades de transporte para os casos com interações spin-órbita e modulação.

O estado inicial é dado por:

$$
\left\langle\Psi_{0}\right\rangle=e^{i k n a} e^{-\left(n-n_{0}\right)^{2} / 2 \sigma^{2}} / A
$$

temos que o $\sigma$ é a largura da gaussiana, $n_{0}$ é o centro do pacote, $\hbar k$ momento linear e $A$ é o fator de normalização. Em todas as simulações consideramos spin inicial como down. E utilizaremos as unidades de medidas descritas na Lista de símbolos (página 10).

\subsection{Influência do termo $H_{D R}$}

Considerando apenas a interação spin-órbita, em que os termos modulados são desligados, temos que o hamiltoniano é dado por:

$$
H=H_{0}+H_{D R}
$$

Para obter a energia total consideramos o estado inicial dado pela gaussiana, eq. (3.1) e utilizando as expressões (2.28) e (2.29) para obter a curva da energia em função de $k$ conforme a figura abaixo:

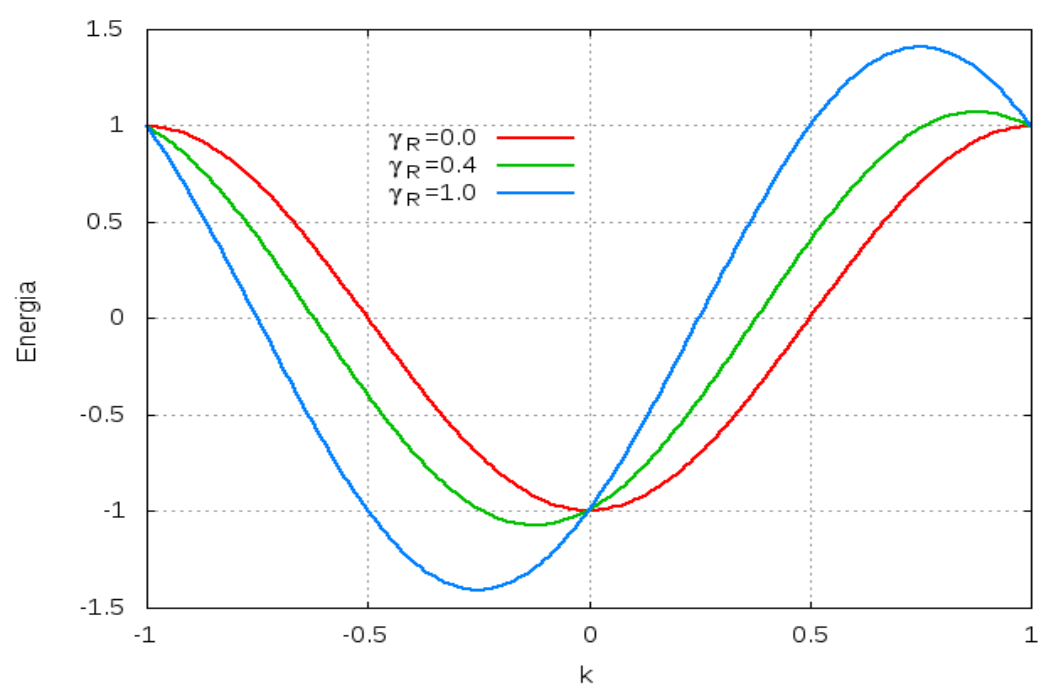

Figura 14 - Energia em função do $k$ para vários $\gamma_{R}$. 
As curvas obtidas na Fig. 14 são similares à curva da Fig. 6 referente ao modelo tight-binding. Verificamos também que as curvas da figura anterior são similares entre si, com mudança na amplitude e na fase, que depende do valor da interação $\gamma_{e f f}$. Esse resultado pode ser explicado observando diretamente a soma dos hamiltonianos $H_{0}$ e $H_{D R}$, que podem ser escritos da seguinte maneira:

$$
\begin{aligned}
H_{0}+H_{D R}= & -W \sum_{n, \tau}(|n, \tau\rangle\langle n+1, \tau|+| n+1, \tau\rangle\langle n, \tau|)-\mu \sum_{n, \tau}|n, \tau\rangle\langle n, \tau| \\
& -i \gamma_{e f f} \sum_{n, \tau} \tau(|n, \tau\rangle\langle n+1, \tau|+| n+1, \tau\rangle\langle n, \tau|)
\end{aligned}
$$

Após aplicar a transformada de Fourier [15] sobre a eq. (3.3) obtemos a equação abaixo:

$$
H_{0}+H_{D R}=\sum_{k, \tau= \pm} E_{\tau}^{(0)}(k)|k, \tau\rangle\langle k, \tau|
$$

onde:

$$
E_{\tau}^{(0)}(k)=-2 \tilde{W} \cos \left[\left(k+\tau q_{0}\right) a\right]-\mu
$$

$\operatorname{com} \tilde{W}=\sqrt{W^{2}+\gamma_{e f f}^{2}}$ e $q_{0} a=\arctan \left(\gamma_{e f f} / W\right)$ e onde $a$ é a constante da rede [5].

As energias dos hamiltonianos $H_{0}+H_{D R}$ em função de $k$ e para cada orientação do spin $\tau$ é obtida através da eq. (3.5).

Verifica-se que apesar do $k$ ser igual a zero, ele possui velocidade e quando $k$ é diferente de zero, e nesse caso foi um $k$ diferenciado, não apresenta velocidade. Isso é consequência da relação de dispersão, onde a velocidade do pacote $v$ está associado não ao $k$ e sim à derivada da energia em relação a $k$ como mostra a eq. (3.6)

A velocidade de grupo é dada por [8, p. 108]:

$$
v_{g}=d E / d k
$$

Nas figuras subseqüentes mostraremos em um modelo em 3D como o pacote se comporta no decorrer do tempo.

A Fig. 15 apresenta um sistema sem modulação com o $\gamma_{R}=0.4$, e é possível perceber que o sistema deslocou para o lado. Isso acontece porque $\gamma_{R}$ fornece uma 
velocidade inicial para o pacote. Já na Fig. 16, foi fornecido um $k$ inicial igual a 0.12 (em unidades de $\pi / a$ ) e o sistema ficou localizado no centro. Não houve deslocamento, e isso acontece porque para esse valor de $k$ a derivada da energia em função de $k$ se anula.

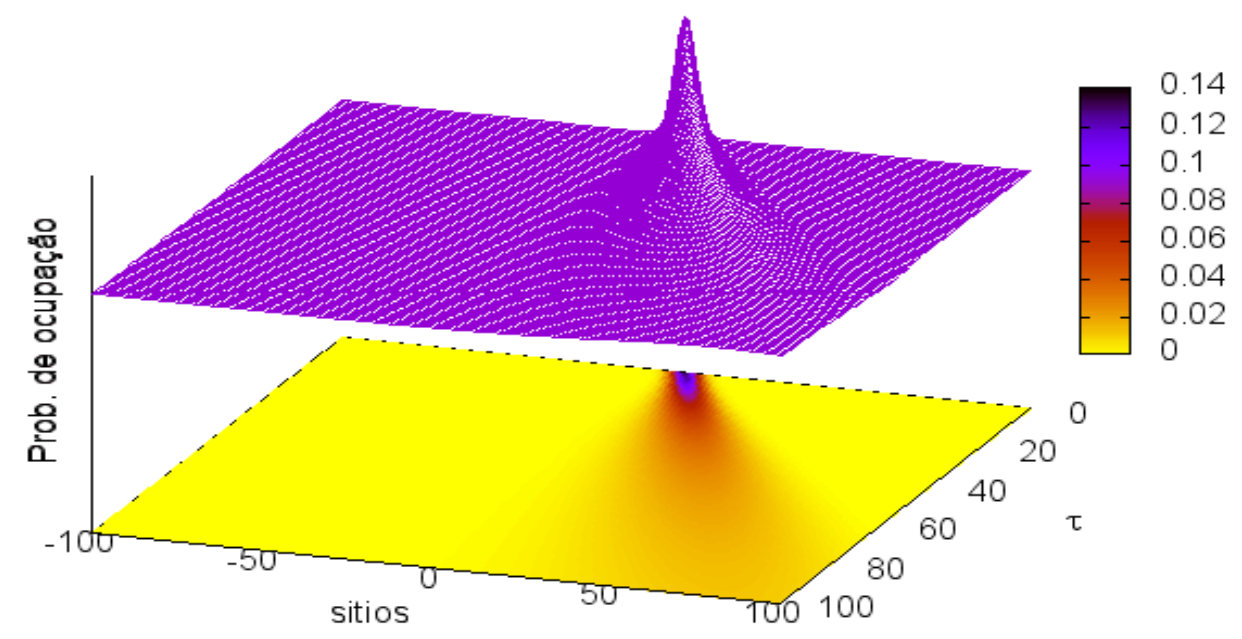

Figura 15 - Propagação eletrônica com apenas $\gamma_{R}$ ligado para $\gamma_{R}=0.4, \sigma=3.0 \mathrm{k}=0.0$.

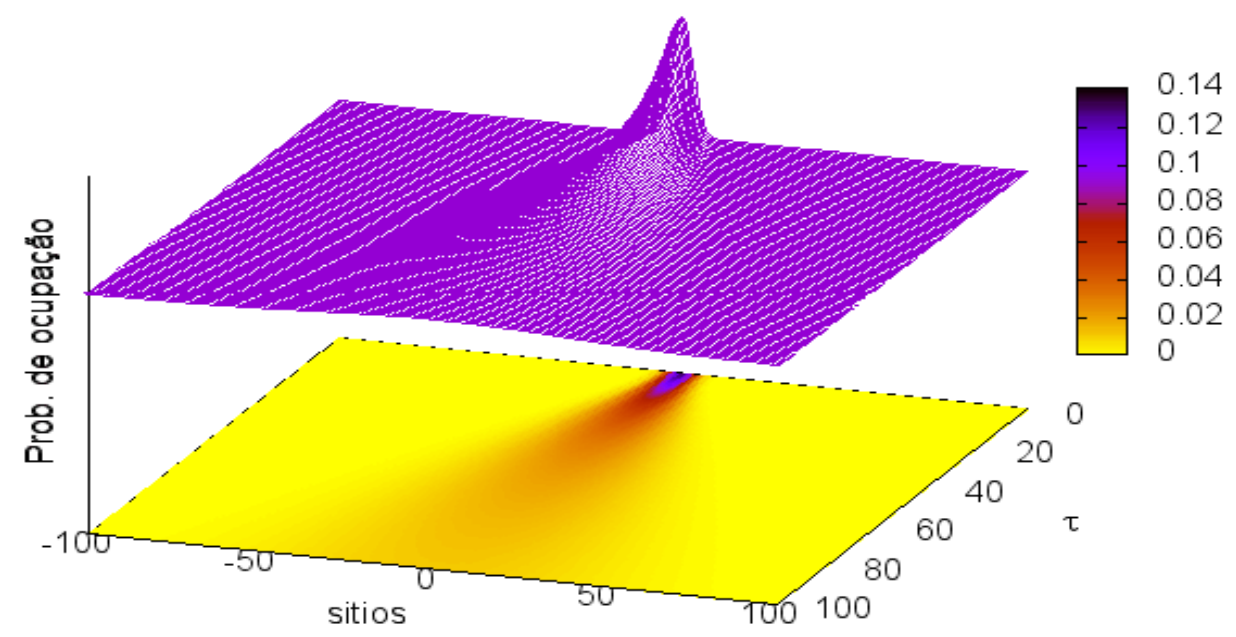

Figura 16 - Propagação eletrônica com apenas $\gamma_{R}$ ligado para $\gamma_{R}=0.4, \sigma=3.0 \mathrm{k}=0.12$. 


\subsection{Influência dos termos do $H_{\text {mod }}$}

O sistema modulado depende de várias variáveis. Nesse sentido, será feito um estudo do comportamento variando cada uma dessas grandezas separadamente.

Para a avaliar a influência dos termos do $H_{\text {mod }}$ fixamos o número de sítios $N=500$ e o valor de $\sigma=3$, variamos os outros parâmetros um de cada vez e analisamos os resultados.

\subsubsection{Influência do termo $\gamma_{\text {mod }}$}

Variando o valor de $\gamma_{\text {mod, }}$, fixando os outros parâmetros e o número de sítios $N=500$, também é possível observar a existência de um deslocamento de parte do pacote de onda, o que indica a presença de uma velocidade inicial. A explicação para esse acontecimento deve-se ao fato de que apesar de $k$ deixar de ser um bom número quântico, pois o momento deixa de comutar com o operador hamiltoniano, existe uma herança de comportamento do termo $H_{D R}$. Portanto conclui-se que, o pacote mesmo com $k=0$. é capaz de gerar um deslocamento do pacote, pois apresenta uma velocidade de grupo.

As Figs. 17, 18 e 19 indicam que um aumento do valor de $\gamma_{\text {mod }}$ implica no deslocamento do pacote, descentralizando-o. Observe que uma parte da função de onda permanece em seu estado inicial e outra parte sofre um deslocamento para o lado, isso acontece porque o comportamento dinâmico também depende fortemente da sua condição inicial.

Verifica-se também que, na Fig. 20, que o aumento de $\gamma_{\text {mod }}$ implicou no aumento do número de sítios que participam do pacote, a probabilidade do elétron estar confinado em apenas uma região diminuiu pois a função de onda percorreu uma região maior no decorrer do tempo e também diminuiu a probabilidade do elétron de estar no seu estado inicial.

De acordo com [15], existem autoestados considerados metálicos (proporciona a delocalização) e autoestados isolantes (proporciona a localização). Isto explica o comportamento da função de onda altamente dependente das condições iniciais. Se o estado inicial (representado pela gaussiana) é composto por um número maior de estados metálicos, a probabilidade do pacote delocalizar é maior e se for composto por maior parte por estados isolantes, a probabilidade maior é de localização.

É obvio que os autoestados não dependem das condições iniciais, dependem apenas dos parâmetros do hamiltoniano, mas o comportamento do pacote depende das condições iniciais.

Os casos em que os gaps surgem nas bandas de energia são crescentes e tem 
como consequência um comportamento mais localizante.

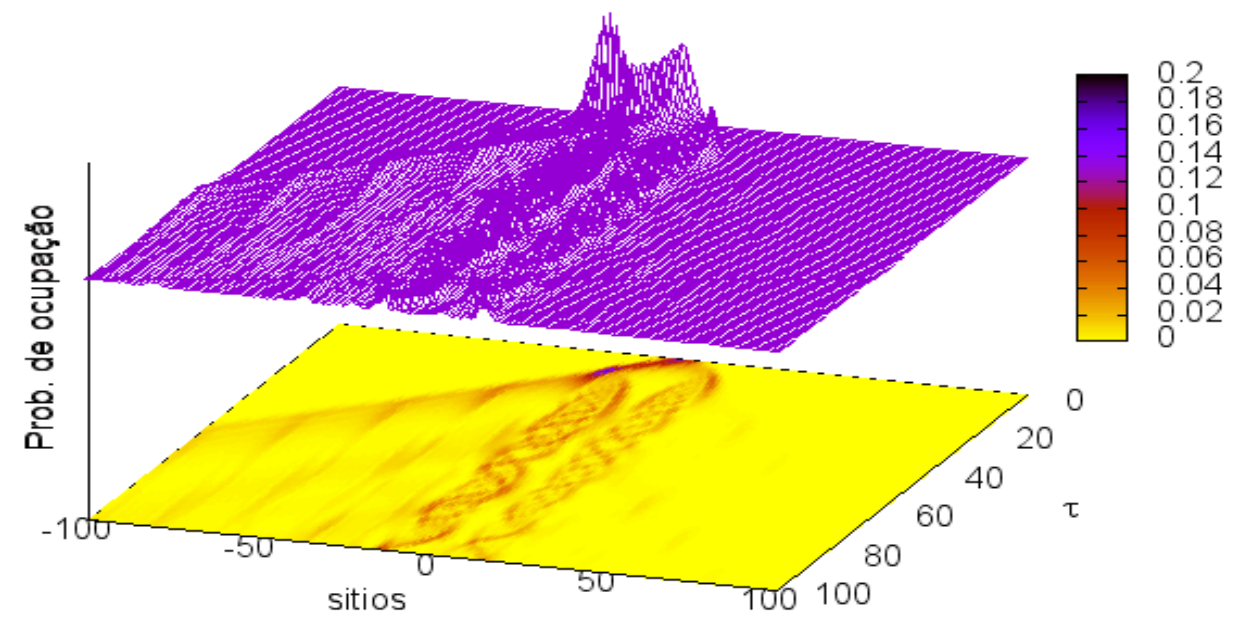

Figura 17 - Propagação eletrônica com parâmetros do $H_{\text {mod }}$ para $\mathrm{q}=0.05, \mu=5.0$, $\mu_{\text {mod }}=2.5, \gamma_{\text {mod }}=0.5, \sigma=3.0, \mathrm{k}=0.0$.

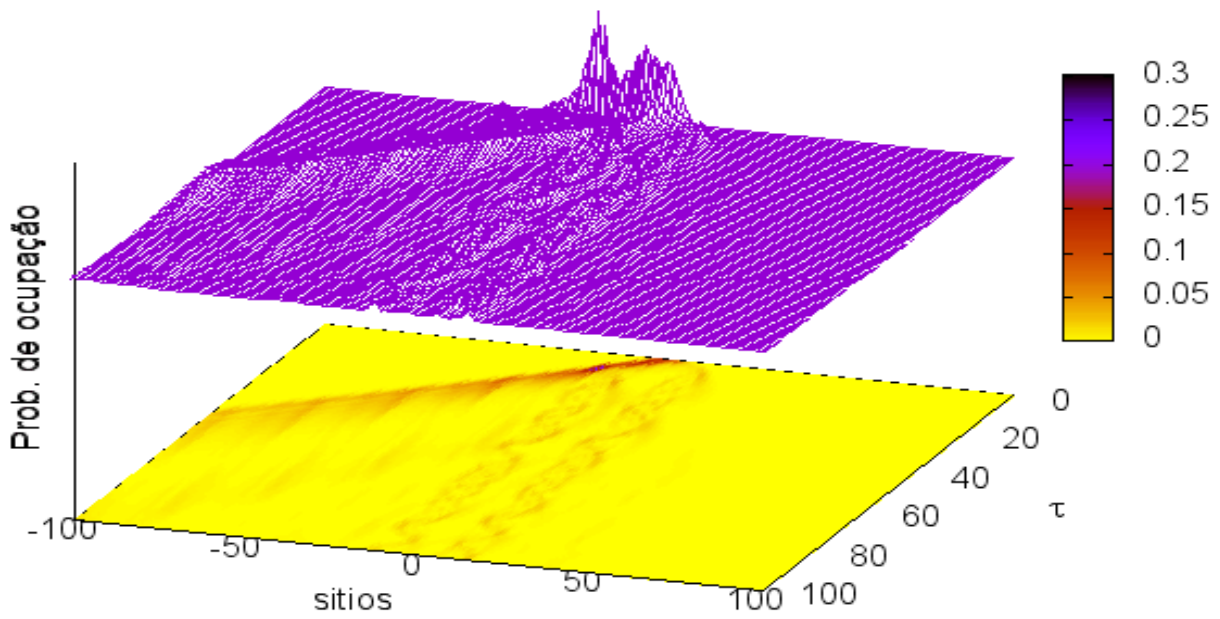

Figura 18 - Propagação eletrônica com parâmetros do $H_{\text {mod }}$ para $\mathrm{q}=0.05, \mu=5.0$, $\mu_{\text {mod }}=2.5, \gamma_{\text {mod }}=1.0, \sigma=3.0, \mathrm{k}=0.0$. 


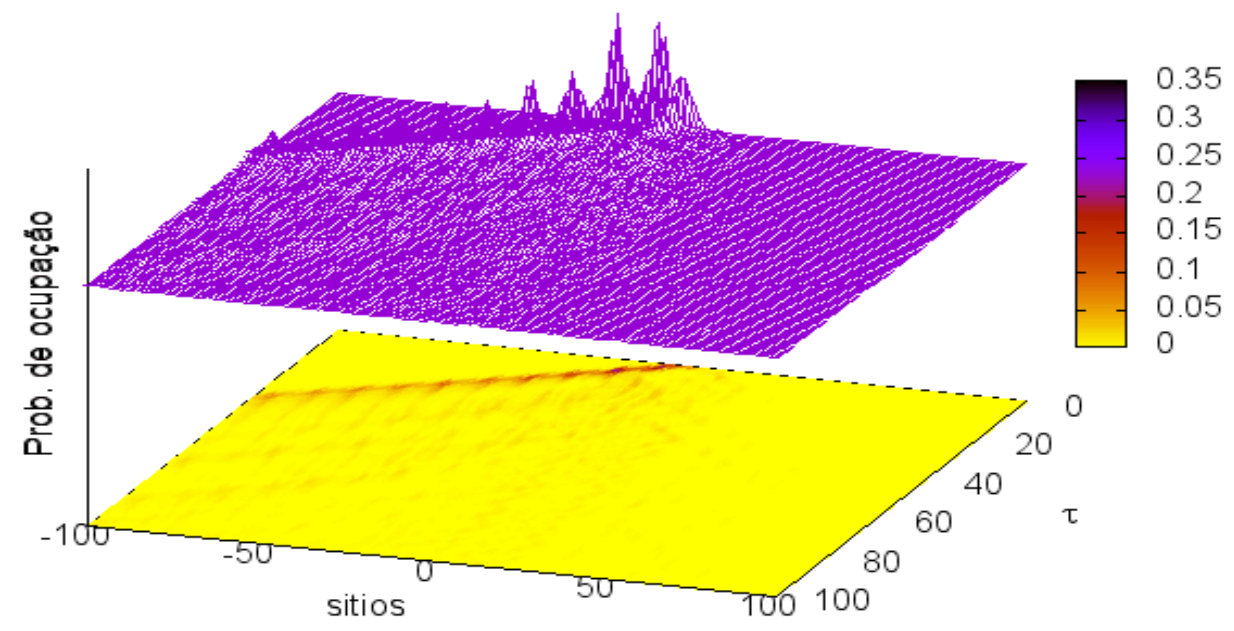

Figura 19 - Propagação eletrônica com parâmetros do $H_{\text {mod }}$ para $\mathrm{q}=0.05, \mu=5.0$, $\mu_{\text {mod }}=2.5, \gamma_{\text {mod }}=2.0, \sigma=3.0, \mathrm{k}=0.0$.
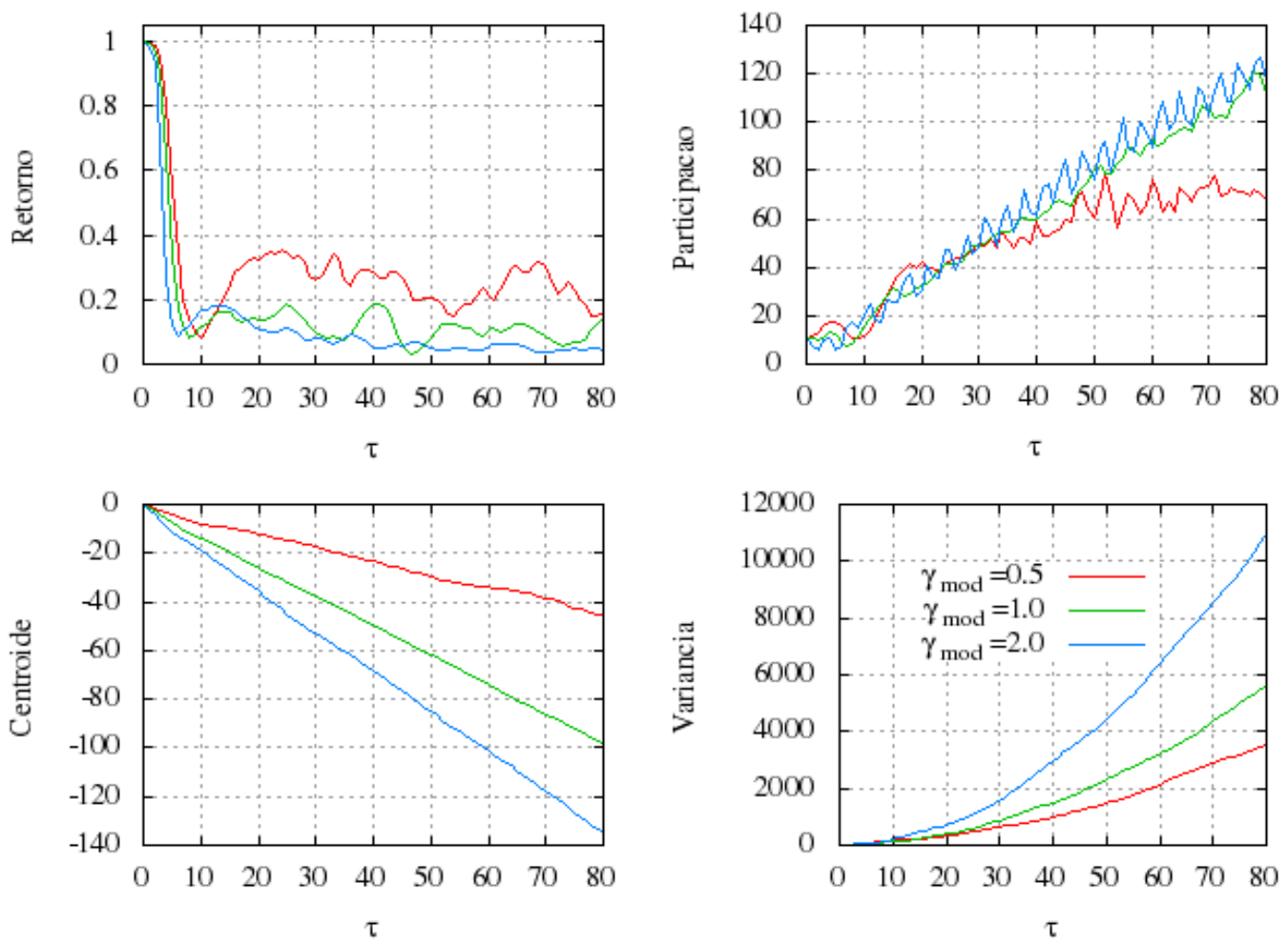

Figura 20 - Evolução temporal do retorno, participação, do centroide e da variância com parâmetros do $H_{\text {mod }}$ para q=0.05, $\mu=5.0, \mu_{\text {mod }}=2.5, \gamma_{\text {mod }}=$ variando, $\sigma=3.0, \mathrm{k}=0.0$. 


\subsubsection{Influência do termo $\gamma_{\text {mod }}$ com $\mathrm{k}=0.5$}

Quando o valor de $k=0.5$ as medidas mudam significativamente em comparação com $k=0.0$.

O aumento do $\gamma_{\text {mod }}$ implica na redução do número de sítios que participam do pacote, bem como da variância e aproximadamente $75 \%$ do pacote de onda permanece mais localizado, ou seja, a probabilidade do elétron encontrar-se confinado em determinada região é de $75 \%$. Pode-se concluir, nesse sentido, que o momento inicial pode localizar fortemente o pacote de onda no centro. Esse comportamento lembra o descrito na seção anterior pelo $H_{D R}$, porém a relação não é a mesma, pois é um pouco mais complexa e não foi definida neste trabalho.

As condições iniciais também explicam esse comportamento, observe que boa parte dos autoestados foram excitados inicialmente pelo momento linear inicial $k=0.5$, porque as condições iniciais é composta na maior parte por estados isolantes, a probabilidade maior é da localização. Quando se tem vários gaps, a probabilidade de excitar estados localizados é maior, então normalmente ele vai ficar mais preso.
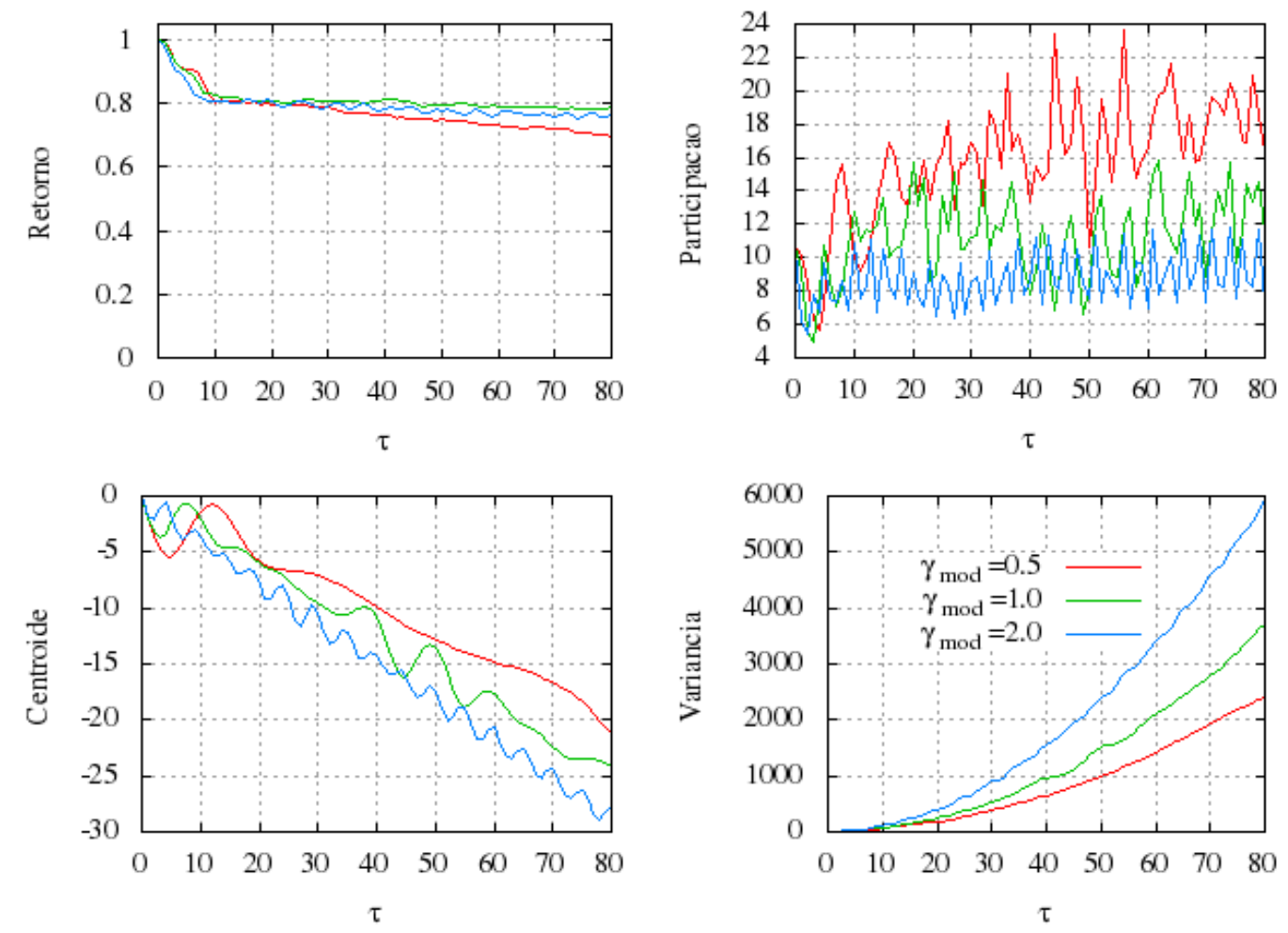

Figura 21 - Evolução temporal do retorno, participação, do centroide e da variância com parâmetros do $H_{\text {mod }}$ para q=0.05, $\mu=5.0, \mu_{\bmod }=2.5, \gamma_{\text {mod }}=$ variando, $\sigma=3.0, \mathrm{k}=0.5$.

Comparando os gráficos em 3D para o valor de $\mathrm{k}=0.0$ e $\mathrm{k}=0.5$, no primeiro caso, 
mesmo sem fornecer um $k$ inicial o pacote sofreu um deslocamento já no segundo caso observa-se o contrário, pois o pacote ficou fortemente centralizado, ou seja, não variou se comparado com o seu estado inicial.

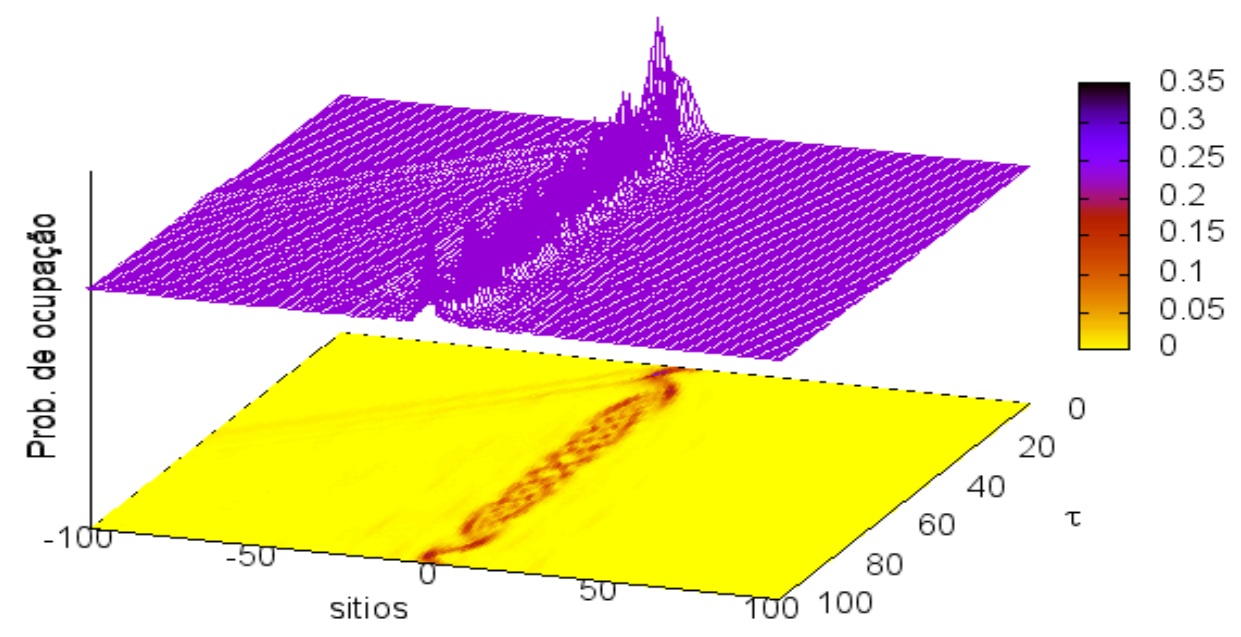

Figura 22 - Propagação eletrônica com parâmetros do $H_{\text {mod }}$ para $\mathrm{q}=0.05, \mu=5.0$, $\mu_{\text {mod }}=2.5, \gamma_{\text {mod }}=0.5, \sigma=3.0, \mathrm{k}=0.5$.

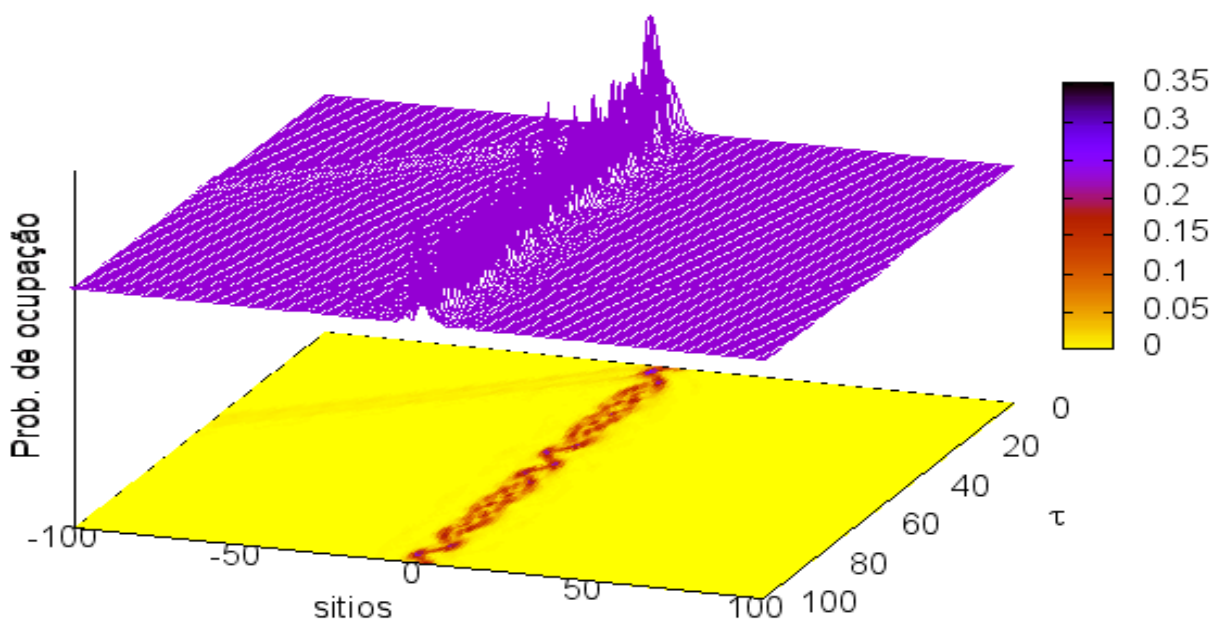

Figura 23 - Propagação eletrônica com parâmetros do $H_{\text {mod }}$ para $\mathrm{q}=0.05, \mu=5.0$, $\mu_{\text {mod }}=2.5, \gamma_{\text {mod }}=1.0, \sigma=3.0, \mathrm{k}=0.5$. 


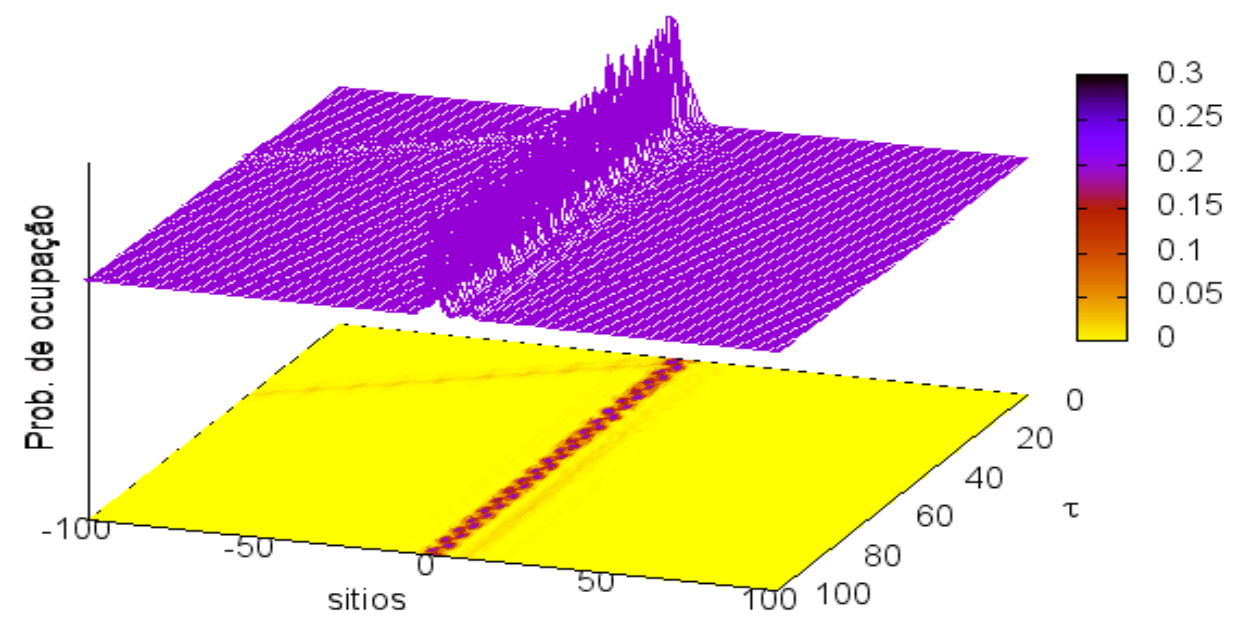

Figura 24 - Propagação eletrônica com parâmetros do $H_{\text {mod }}$ para $\mathrm{q}=0.05, \mu=5.0$, $\mu_{\text {mod }}=2.5, \gamma_{\text {mod }}=2.0, \sigma=3.0, \mathrm{k}=0.5$.

\subsubsection{Influência do termo $\gamma_{D}$}

Nessa seção, será verificada a influência na troca de spin fixando os valores de $\gamma_{R}$ e $\gamma_{m o d}$ e variando o $\gamma_{D}$. A troca de spin esta presente no segundo termo da eq. (2.9) do capitulo 2, que esta associada ao $\operatorname{sen}(2 \theta)$.

Na Fig. 25, o gráfico Retorno 1 apresenta o valor de $\gamma_{D}=0.5$ e o Retorno $2 \gamma_{D}=$ 1.0. O spin down para $\gamma_{D}=0.5$ o pacote fica um pouco mais localizado se comparado com o spin up. Com o aumento de $\gamma_{D}$ a probabilidade do elétron ficar confinado em apenas uma região diminui no decorrer do tempo.

Com o gráfico da norma é possível verificar que o programa está trabalhando corretamente, pois a soma da norma associado ao spin é igual a 1, sendo que existe uma probabilidade de $60 \%$ do elétron ficar com spin down e $40 \%$ com spin up.

Observe nas Figs. 26 e 27 que a probabilidade do spin up ficar mais localizado no centro do pacote, ou seja, se espalhar menos, é maior do que para o spin down, isso porque o spin up não sofre a mesma influência da velocidade de grupo que o down. 

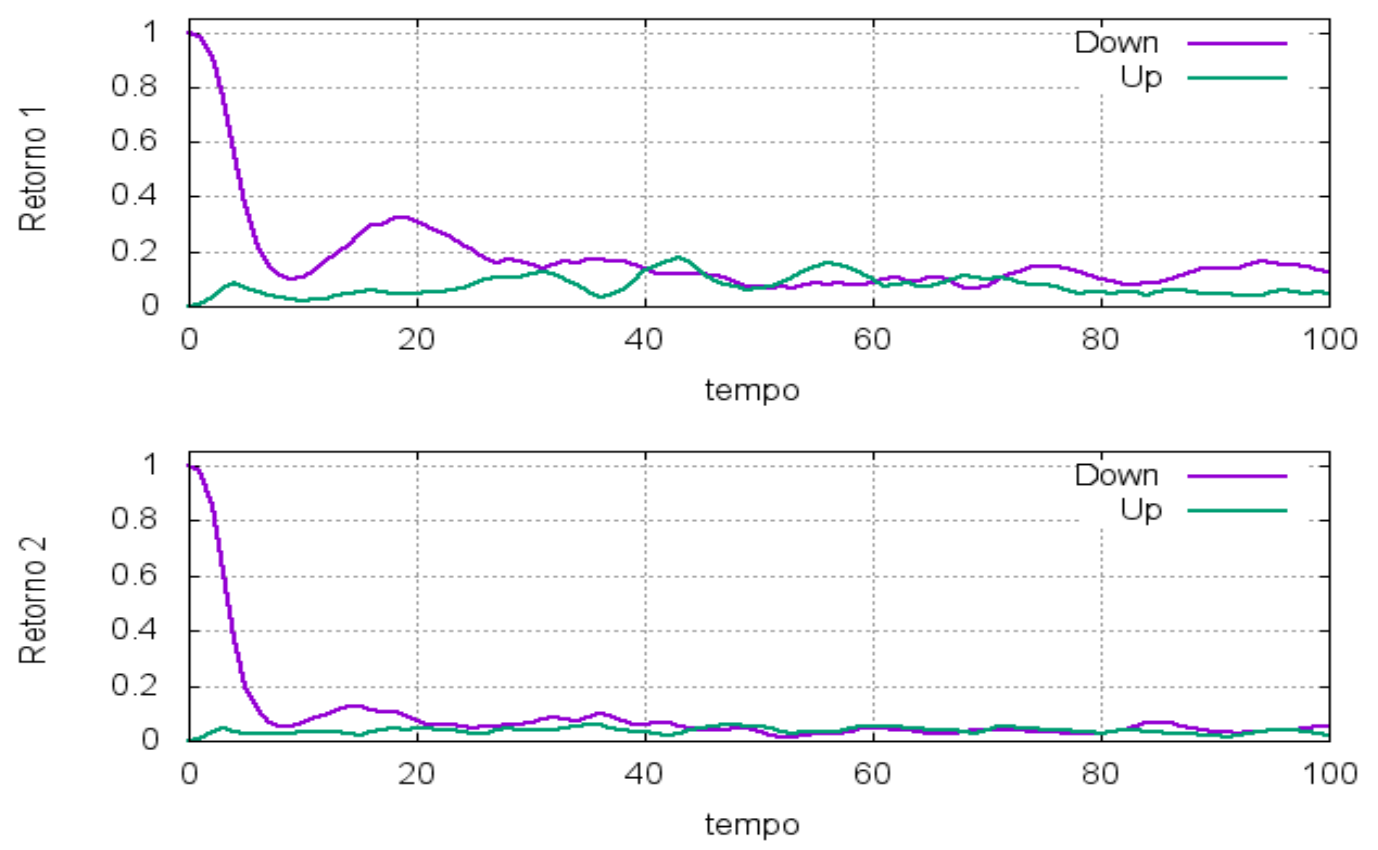

Figura 25 - Evolução temporal do retorno com parâmetros do $H_{\text {mod }}$ para $q=0.05, \mu=5.0$, $\mu_{\text {mod }}=2.5, \gamma_{\text {mod }}=0.5, \gamma_{R}=0.5, \gamma_{D}=0.5$ e $1.0, \sigma=3.0, \mathrm{k}=0.0$.
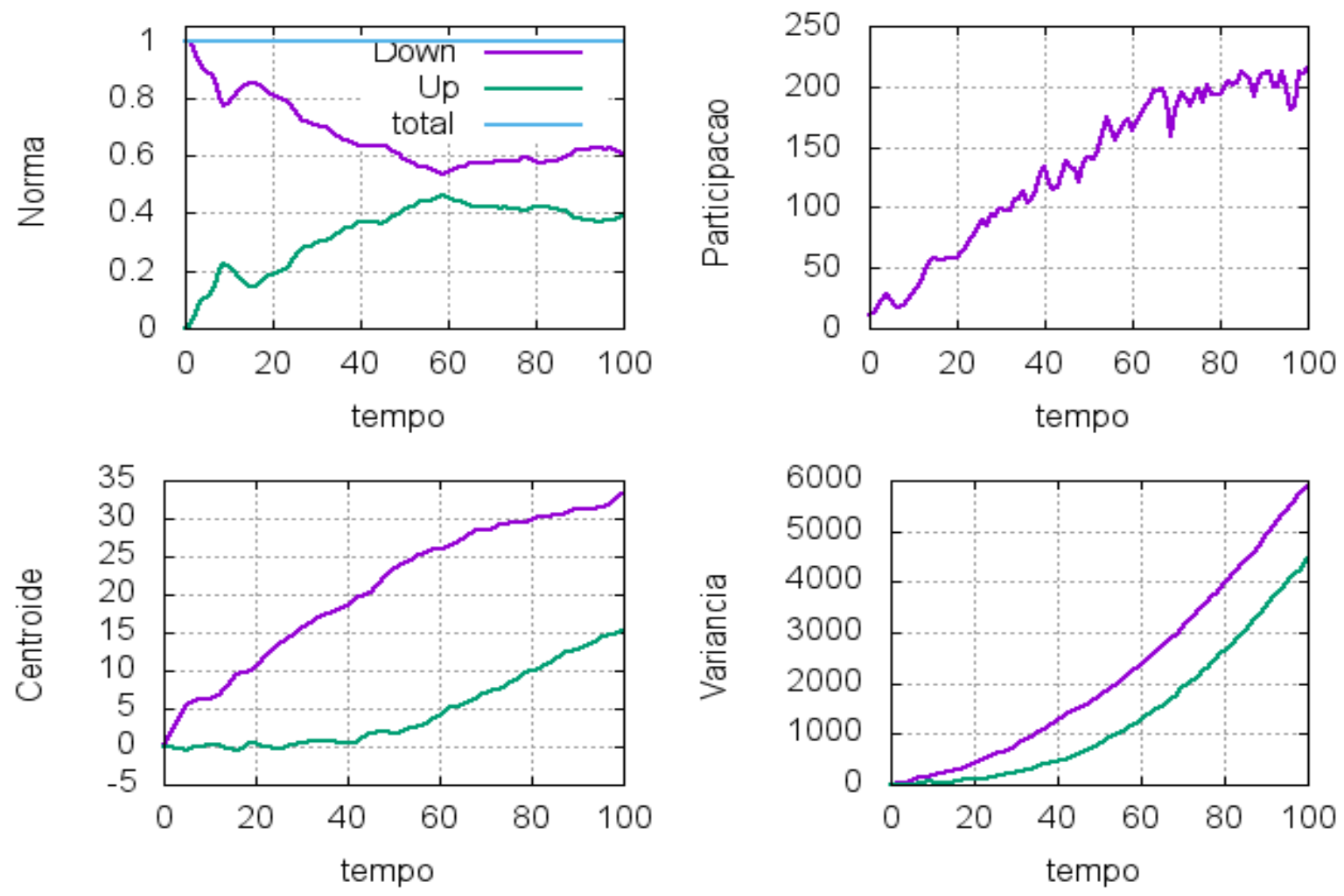

Figura 26 - Evolução temporal do retorno, participação, do centroide e da variância com parâmetros do $H_{\text {mod }}$ para $\mathrm{q}=0.05, \mu=5.0, \mu_{\text {mod }}=2.5, \gamma_{\text {mod }}=0.5, \gamma_{R}=0.5$, $\gamma_{D}=0.5, \sigma=3.0, \mathrm{k}=0.0$. 
Para $\gamma_{D}=1.0$ o comportamento é um pouco diferente. A localização do pacote diminuiu, o spin up esta mais localizado no centro e a variância se encontra igual a 2000 enquanto que para o spin down a variância aumentou quatro vezes mais, isso porque a tendência dos elétrons com spin up ficarem presos é maior.

Com o aumento do $\gamma_{D}$ houve variação nas bandas de energia e na dependência da relação de dispersão da energia com k. Quando há um numero grande de bandas, isto leva o pacote de onda a se localizar em determinados sítios.

Não houve mudança significativa no numero de sítios que participam do pacote de onda, com a variação do $\gamma_{D}$.
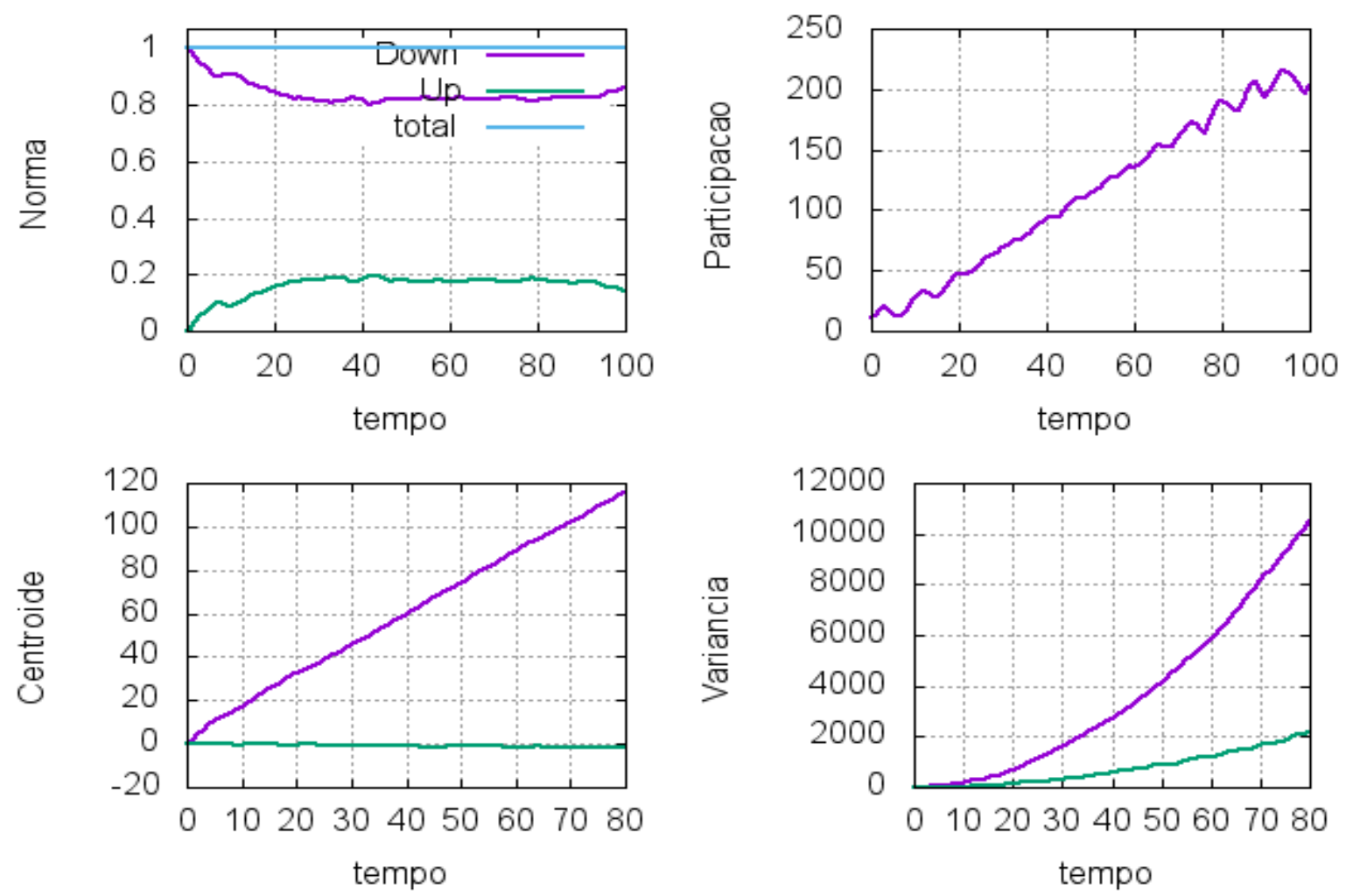

Figura 27 - Evolução temporal do retorno, participação, do centroide e da variância com parâmetros do $H_{\text {mod }}$ para $\mathrm{q}=0.05, \mu=5.0, \mu_{\text {mod }}=2.5, \gamma_{\text {mod }}=0.5, \gamma_{R}=0.5$, $\gamma_{D}=1.0, \sigma=3.0, \mathrm{k}=0.0$, com spin $u p$.

Veja que nas Figs. 28 e 29 é possível confirmar algumas das analises feitas com os gráficos da evolução temporal. Com as figuras em 3D tem-se uma visualização melhor da localização e do espalhamento do pacote. As Figs. 28 e 29 mostram a diferença na propagação eletrônica para os spin down e up. Note que a probabilidade de ocupação é sempre maior no spin down, isso porque os elétrons foram soltos com spin down, porem parte dos elétrons mudam para o spin $u p$, por isso uma probabilidade menor para o spin $u p$. 


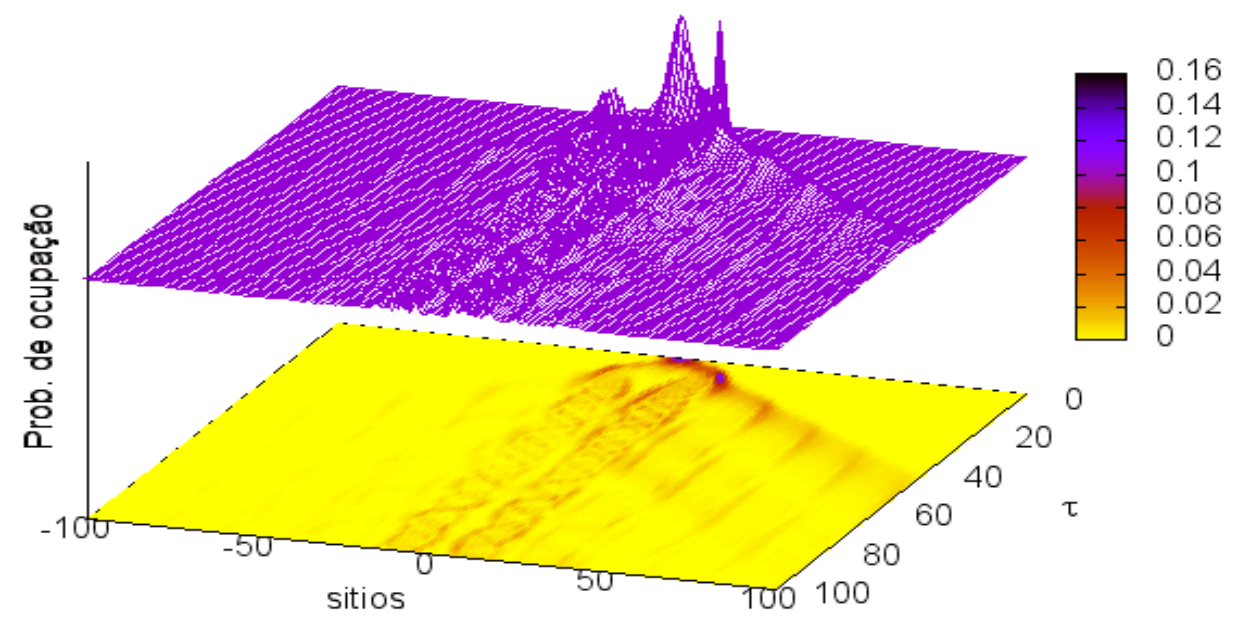

Figura 28 - propagação eletrônica com parâmetros do $H_{\text {mod }}$ para $\mathrm{q}=0.05, \mu=5.0$, $\mu_{\text {mod }}=2.5, \gamma_{\text {mod }}=0.5, \gamma_{R}=0.5, \gamma_{D}=0.5, \sigma=3.0, \mathrm{k}=0.0$, com spin down.

A Fig. 28 mostra um menor espalhamento da função de onda, se comparado com a Fig. 29. A função de onda com spin down espalham menos do que com spin up, a explicação é que a velocidade de grupo para cada spin é diferente. Podemos notar que quando aumentamos o valor de $\gamma_{D}$ para 1.0 o pacote fica mais localizado em uma região para os dois spins. Note também que na Fig. 28 a velocidade com que o pacote foi solto é maior se comparado com a Fig. 30. 


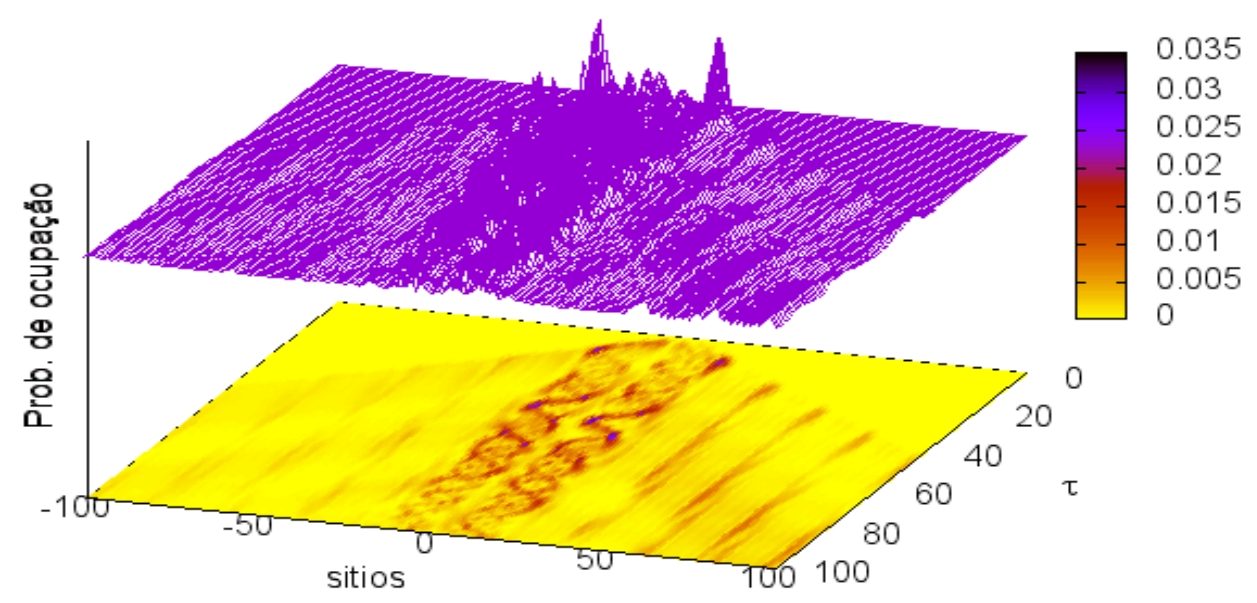

Figura 29 - propagação eletrônica com parâmetros do $H_{\bmod }$ para $\mathrm{q}=0.05, \mu=5.0$, $\mu_{\text {mod }}=2.5, \gamma_{\text {mod }}=0.5, \gamma_{R}=0.5, \gamma_{D}=0.5, \sigma=3.0, \mathrm{k}=0.0$, com spin $u p$.

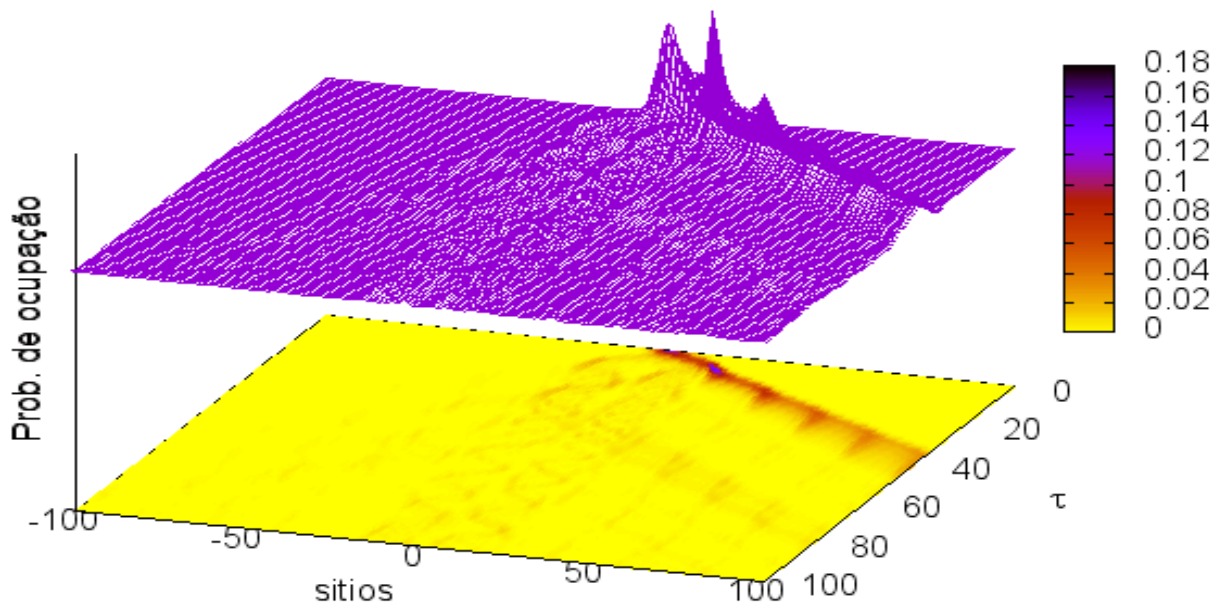

Figura 30 - propagação eletrônica com parâmetros do $H_{\text {mod }}$ para $\mathrm{q}=0.05, \mu=5.0$, $\mu_{\text {mod }}=2.5, \gamma_{\text {mod }}=0.5, \gamma_{R}=0.5, \gamma_{D}=1.0, \sigma=3.0, \mathrm{k}=0.0$, com spin down. 


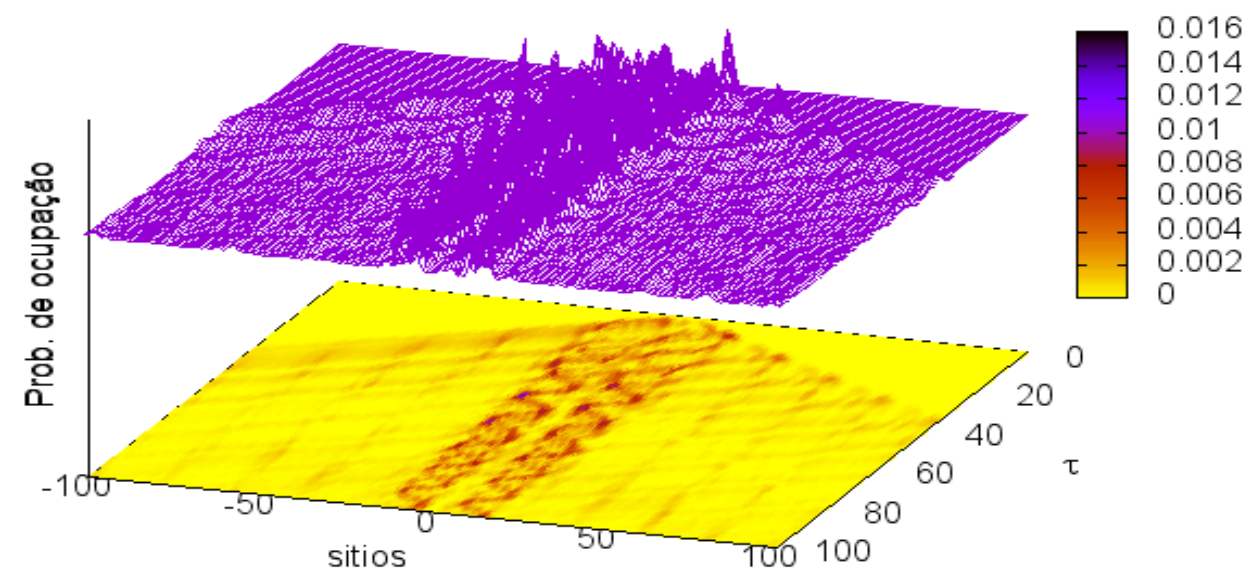

Figura 31 - propagação eletrônica com parâmetros do $H_{\text {mod }}$ para $\mathrm{q}=0.05, \mu=5.0$, $\mu_{\text {mod }}=2.5, \gamma_{\text {mod }}=0.5, \gamma_{R}=0.5, \gamma_{D}=1.0, \sigma=3.0, \mathrm{k}=0.0$, com spin $u p$.

\subsection{Influência do número de onda da modulação externa}

O valor de $q$, número de onda do potencial modulado, é fundamental na determinação do número de gaps que aparecem na banda de energia. Se $q \in \mathbb{Q}$ (Conjunto dos Racionais), ele pode ser escrito como a razão de dois inteiros, sendo o número de bandas determinado pelo denominador.

Quando são inseridos os nanocapacitores carregados positivamente os elétrons são atraídos pelas cargas positivas e ficam confinados embaixo deles. Esse nanocapacitores são inseridos com espaçamentos iguais entre eles, na Fig 32 a distância é de 7 sítios. 


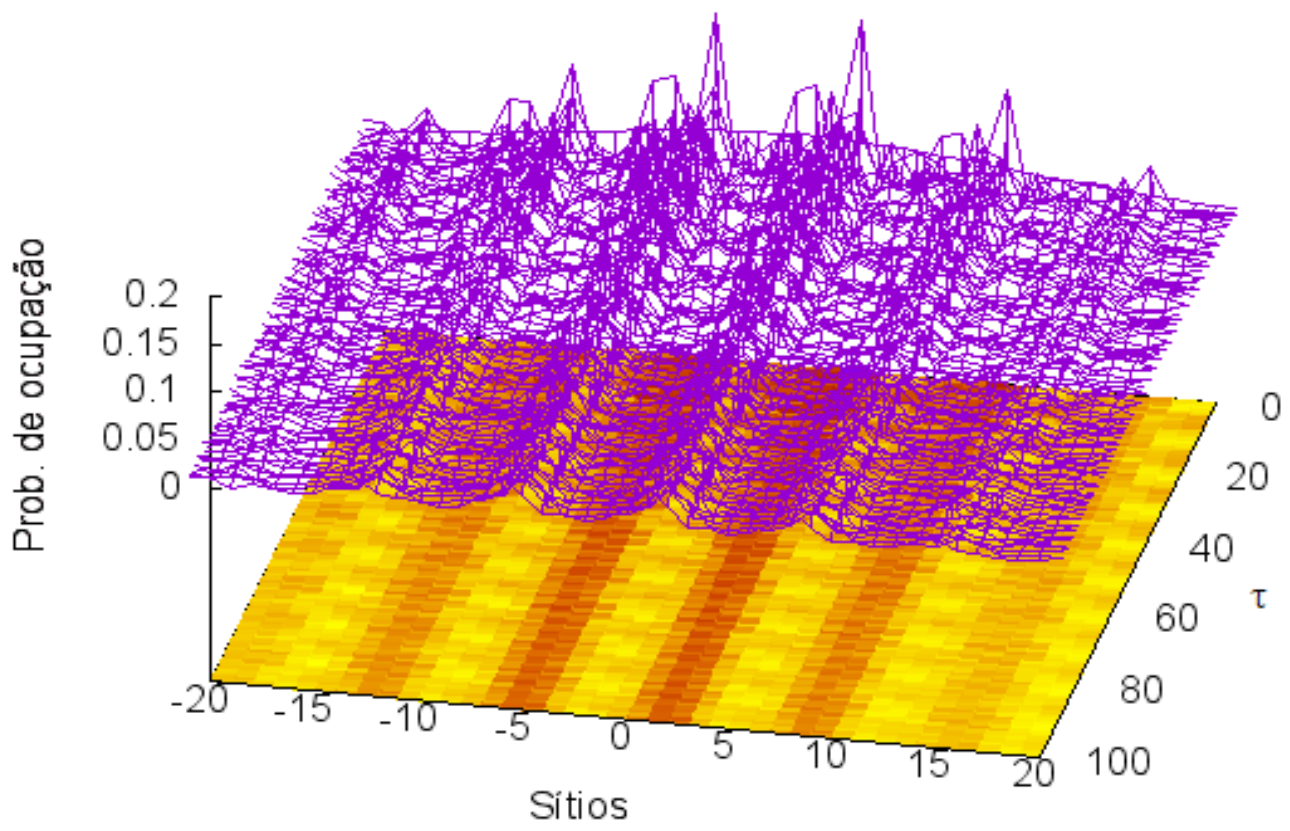

Figura 32 - Propagação eletrônica para $q=1 / 7$.

Para verificar de forma mais clara a distância entre os sítios fizemos um corte no tempo $80 \tau$ na figura acima.

A Fig. 33 mostra que entre os nanocapacitores há sete sítios, onde $a$ é a distância entre os sítios, sendo que $7 a$ representa a distância entre os capacitores.

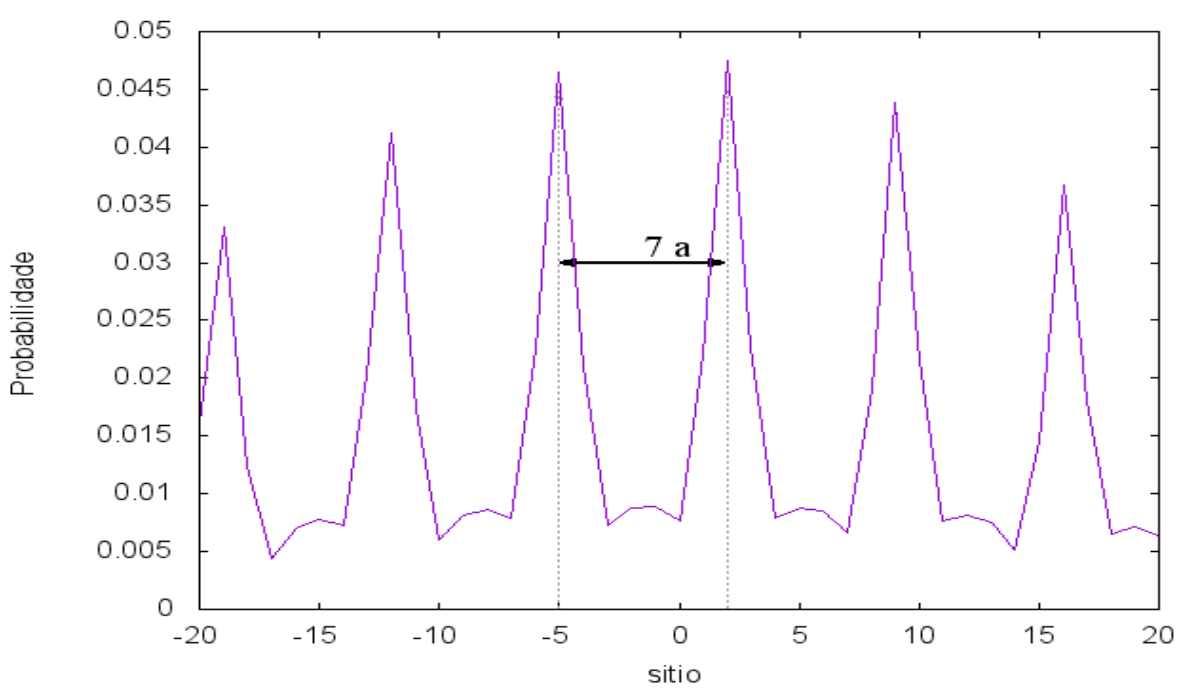

Figura 33 - Distância entre os nanocapacitores para $q=1 / 7$.

Para entender porque o pacote com o decorrer do tempo se fixa em sítios espaçados de 7 em 7 , isso porque existem 7 sítios entre os nanocapacitores e eles 
atraem o elétron para esta posição.

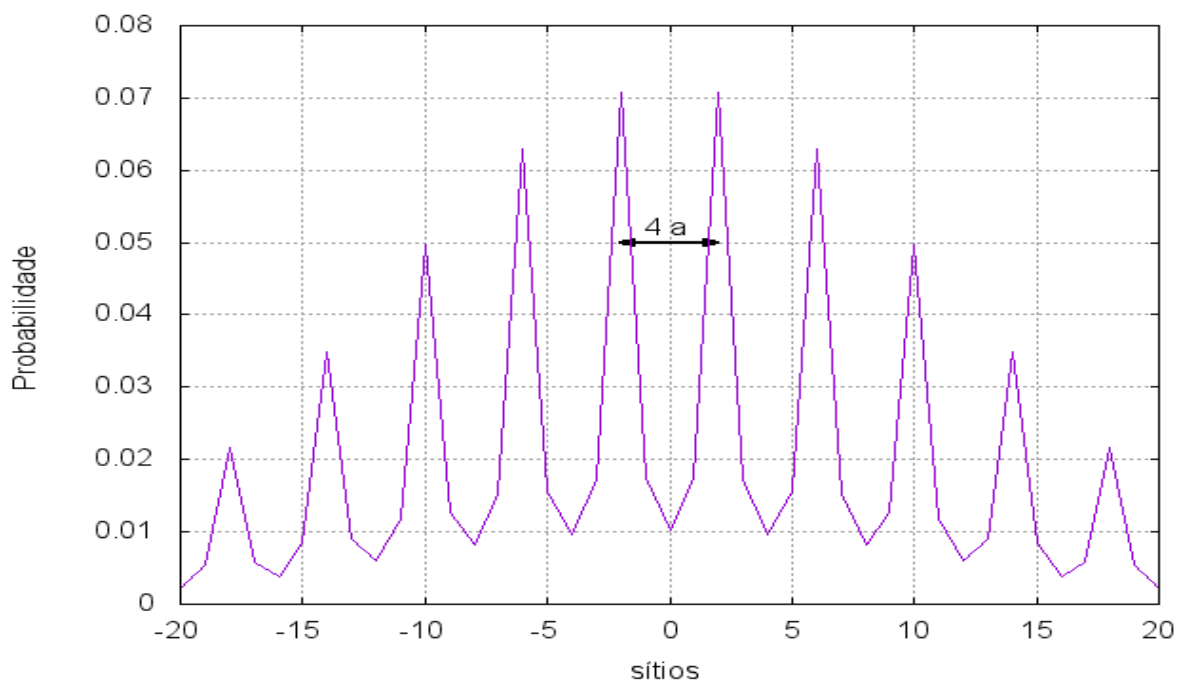

Figura 34 - Distância entre os nanocapacitores para $\mathrm{q}=1 / 4$.

Para $q=1 / 4$ os nanocapacitores estão espaçados em uma distância igual a $4 a$ como mostra a Fig. 34.

Na Fig. 35 o valor de $q \notin \mathbb{Q}$, isto é, não existe uma distância periódica entre os sítios e os nanocapacitores, porque se trata de um valor imensurável, acarretando uma não localização do pacote de onda. Neste caso, todos os autoestados do hamiltoniano são metálicos.

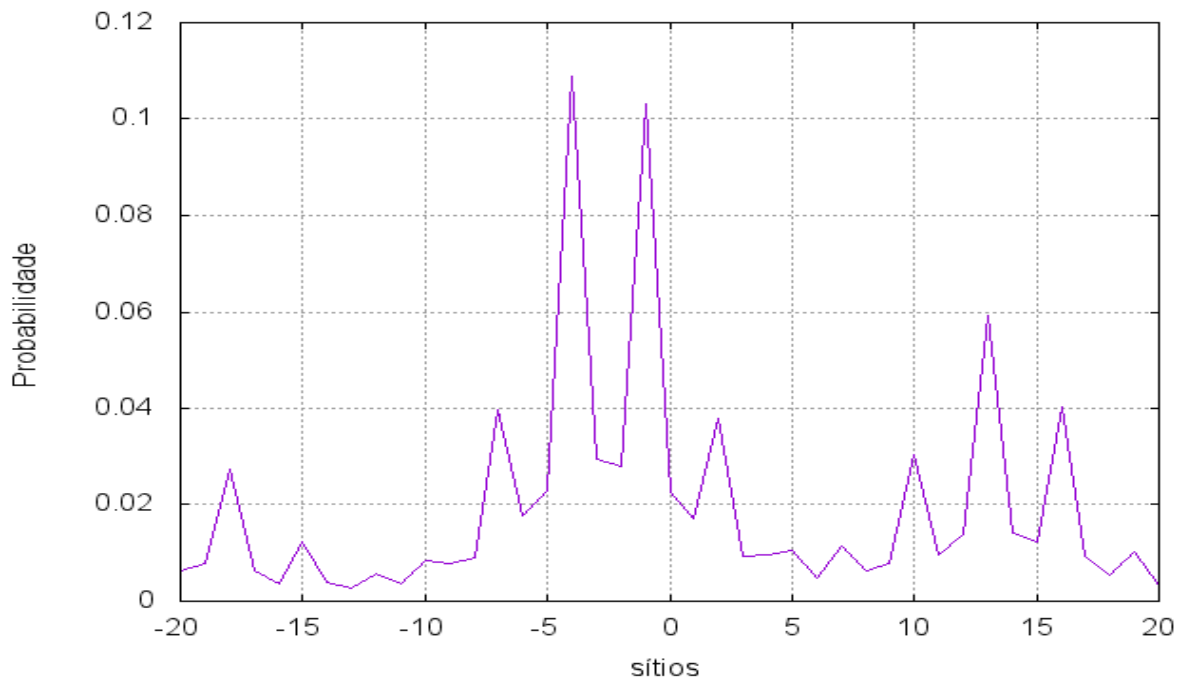

Figura 35 - Distância entre os nanocapacitores para $q=\sqrt{2} / 2$. 


\section{Conclusão}

Neste trabalho, estudamos a função de onda no sistema cristalino com base no modelo tight-binding, que se trata de um modelo relativamente simples que os demais e que pode fornecer resultados satisfatórios. Apresentamos alguns conceitos que serviram de base nos capítulos subsequentes e fizemos uma análise de comportamento dinâmico para um sistema com interação spin-órbita e potencial químico modulados.

Para realizar o estudo de comportamento dinâmico utilizamos do método da diagonalização do hamiltoniano para realizar a evolução temporal do pacote de onda e as diversas medidas que caraterizam o transporte dinâmico: norma, centroide, desvio quadratico médio, variância, energia e probabilidade de retorno. Para diagonalização do hamiltoniano foram utilizadas rotinas de cálculo numérico MKL (Intel Math Kernel Library).

Observamos que o momento linear gerou uma menor dispersão do pacote de onda, e também contribuiu para diminuição do número de sítios que participam do pacote de onda, tanto para o caso cristalino quanto para o caso modulado. Podemos entender isto lembrando que pelo princípio de incerteza temos $\Delta x \Delta k>=1$, então, quanto maior $\Delta x$, mais preciso é a medida de $k$ e a dispersão relativa do vetor de onda $\Delta k / k$ diminui quando temos um valor de $k$ cada vez maior.

Identificamos que o termo $\gamma_{\text {mod }}$ provocou deslocamento de parte da função de onda devido à presença da velocidade de grupo. $\mathrm{O}$ momento linear inicial fez o pacote ficar fortemente localizado no centro, porque o estado inicial é composto por um número maior de estados isolantes.

Na interação spin-órbita de Dresselhaus, responsável pela troca de spin, foi observado que também apresenta uma velocidade de grupo, mas que não atinge com a mesma intensidade os spins up e down. A velocidade para cada spin é diferente e vai depender do spin em que o pacote foi solto.

O comportamento dinâmico da função de onda, de ela ser localizada ou não, depende do hamiltoniano e dos seus diversos parâmetros como depende fortemente da sua condição inicial, pois esta vai dizer quais autoestados foram excitados no início, e isso parece ser extremamente relevante para o entendimento do comportamento dinâmico. Para que esta ideia possa ser validada, é necessário um estudo detalhado de quais são os autoestados que são excitados pelo estado inicial. E esse estudo servirá como um trabalho a ser feito a posteriori. 


\section{Referências}

[1] I. Žutić, J. Fabian, and S. Das Sarma, Spintronics: Fundamentals and applications Rev. Mod. Phys., vol. 76, pp. 323-410, Abr 2004.

[2] I. S. Oliveira and V. L. B. Esus, Introdução a Física do Estado Sólido. Editora Livraria da Física, 2005.

[3] S. M. Rezende, Materiais e Dispositivos Eletrônicos. Editora Livraria da Física, 5 ed., 2004.

[4] S. Datta and B. Das, Electronic analog of the electro-optic modulator, Applied Physics Letters, vol. 56, p. 665-667, Dez 1990.

[5] M. Malard, I. Grusha, G. I. Japaridze, and H. Johannesson, Modulated rashba interaction in a quantum wire: Spin and charge dynamics, Phys. Rev. B, vol. 84, p. 075466, Ago 2011.

[6] D. Grundler, Ballistic spin-filter transistor, Phys. Rev. B, vol. 63, p. 161307, Abr 2001.

[7] J. Schliemann, J. C. Egues, and D. Loss, Nonballistic spin-field-effect transistor, Phys. Rev. Lett., vol. 90, p. 146801, Abr 2003.

[8] C. Kittel, Introdução à Física de Estado Sólido. Guanabara Dois, 5 ed., 1978.

[9] W. D. Callister, Ciência e engenharia de materiais: uma introdução. LTC, 5 ed., 2000.

[10] B. Cohen-Tannoudji, Claude. Diu and F. Laloe, Quantum Mechanics. Willey, 1 ed., 1973.

[11] B. Simons and A. Atland, Condesend Matter Field Theory. Cambridge University Press, 2006.

[12] H. N. Nazareno, C. A. A. da Silva, and P. E. de Brito, Dynamical localization in a one-dimensional crystal with an impurity under the action of an electric field, Phys. Rev. B, vol. 50, pp. 4503-4508, Ago 1994.

[13] Intel Math Kernel Library. Reference Manual, Intel Corporation, 2009. Santa Clara, USA. ISBN 630813-054US.

[14] D. Griffiths, Introduction to Quantum Mechanics. Pearson international edition, 2005. 
[15] L. R. Thomas, Transições de fase metal-isolante em um fio quântico submetido a uma interação spin-órbita e a um potencial químico modulados, Dissertação de Mestrado, Universidade de Brasília, 2015.

[16] H. Resnick, Fundamentos de Física 3, Eletromagnetismo. Livros Técnicos e Científicos Editora, 1991.

[17] G. Dresselhaus, Spin-orbit coupling effects in zinc blende structures, Phys. Rev., vol. 100, pp. 580-586, Out 1955.

[18] E. I. Rashba, Properties of semiconductors with an extremum loop .1. cyclotron and combinational resonance in a magnetic field perpendicular to the plane of the loop, Sov. Phys. Solid State, vol. 2, p. 1109, 1960.

[19] G. I. Japaridze, H. Johannesson, and M. Malard, Synthetic helical liquid in a quantum wire, Phys. Rev. B, vol. 89, p. 201403, Mai 2014. 